\title{
Analyzing the atmospheric boundary layer using high-order moments obtained from multiwavelength lidar data: impact of wavelength choice
}

\author{
Gregori de Arruda Moreira ${ }^{1,2,3,4}$, Fábio Juliano da Silva Lopes ${ }^{4}$, Juan Luis Guerrero-Rascado ${ }^{1,2}$, Jonatan João da \\ Silva $^{4,5}$, Antonio Arleques Gomes ${ }^{4}$, Eduardo Landulfo ${ }^{4}$, and Lucas Alados-Arboledas ${ }^{1,2}$ \\ ${ }^{1}$ Andalusian Institute for Earth System Research, Granada, Spain \\ ${ }^{2}$ Department of Applied Physics, University of Granada, Granada, Spain \\ ${ }^{3}$ Astronomy, Geophysics and Atmospheric Science Institute, University of São Paulo, São Paulo, Brazil \\ ${ }^{4}$ Nuclear and Energy Research Institute, São Paulo, Brazil \\ ${ }^{5}$ Federal University of Western Bahia, Bahia, Brazil
}

Correspondence: Gregori de Arruda Moreira (gregori.moreira@usp.br)

Received: 15 February 2019 - Discussion started: 8 April 2019

Revised: 2 July 2019 - Accepted: 3 July 2019 - Published: 7 August 2019

\begin{abstract}
The lowest region of the troposphere is a turbulent layer known as the atmospheric boundary layer (ABL) and characterized by high daily variability due to the influence of surface forcings. This is the reason why detecting systems with high spatial and temporal resolution, such as lidar, have been widely applied for researching this region. In this paper, we present a comparative analysis on the use of lidar-backscattered signals at three wavelengths $(355,532$ and $1064 \mathrm{~nm}$ ) to study the ABL by investigating the highorder moments, which give us information about the ABL height (derived by the variance method), aerosol layer movement (skewness) and mixing conditions (kurtosis) at several heights. Previous studies have shown that the $1064 \mathrm{~nm}$ wavelength, due to the predominance of particle signature in the total backscattered atmospheric signal and practically null presence of molecular signal (which can represent noise in high-order moments), provides an appropriate description of the turbulence field, and thus in this study it was considered a reference. We analyze two case studies that show us that the backscattered signal at $355 \mathrm{~nm}$, even after applying some corrections, has a limited applicability for turbulence studies using the proposed methodology due to the strong contribution of the molecular signature to the total backscatter signal. This increases the noise associated with the high-order profiles and, consequently, generates misinformation. On the other hand, the information on the turbulence field derived from the backscattered signal at $532 \mathrm{~nm}$ is similar to that ob-
\end{abstract}

tained at $1064 \mathrm{~nm}$ due to the appropriate attenuation of the noise, generated by molecular component of backscattered signal by the application of the corrections proposed.

\section{Introduction}

The atmospheric boundary layer (ABL) is the part of the troposphere that is directly or indirectly influenced by the Earth's surface (land and sea) and responds to gases and aerosol particles emitted at the Earth's surface and to surface forcing at timescales of less than a day. Forcing mechanisms include heat transfer, fluxes of momentum, frictional drag and terrain-induced flow modification. The height of this layer $(\mathrm{ABLH})$ varies from hundreds of meters up to a few kilometers, due to the intensification or reduction of convective or mechanical processes with additional contribution from orographic effects. The ABL presents a daily pattern controlled by the energy balance at the Earth's surface. Thus, after sunrise the positive net radiative flux $\left(R_{\mathrm{n}}\right)$ induces the rise of surface air temperature that initiates the convective process, which is responsible for the growth of the so-called mixing layer (ML) or convective boundary layer (CBL). This layer grows over the day, extending the region affected by the convective process until around midday, when it reaches maximum development. Slightly before sunset, the decrease 
in the incoming solar irradiance at the surface results in a radiative cooling of the Earth's surface. This cooling affects the closest air layer, diminishing the convective process. In this way, the CBL disappears and two new layers characterize the ABL, a stable and stratified layer known as the stable boundary layer (SBL) at the bottom and the residual layer (RL) over the latter with characteristics of the previous day's ML (Stull, 1988).

The turbulent features of the ABL are relevant in air quality and weather forecasting and thus are worthy of study. As a rule, the turbulent processes are treated as nondeterministic and, therefore, the turbulence is characterized by its statistical properties. Thus, high-order statistical moments are used to generate information about the turbulent fluctuation field, besides a description about mixing processes in the ABL (Pal et al., 2010).

ABL turbulence has been commonly studied by means of anemometer towers (e.g., Kaimal and Gaynor, 1983) and aircrafts (e.g., Lenschow et al., 1980; Williams and Hacker, 1992; Lenschow et al., 1994; Stull et al., 1997; Andrews et al., 2004; Vogelmann et al., 2012). Nevertheless, the former have a use restricted to regions near the surface, due to their limited vertical range. Aircraft offer an alternative approach that allows for extending the analyses to higher atmospheric layers, but, conversely, they have a reduced time window, thus limiting the period of analysis. Due to the large variability of the ABL characteristics over the day, the use of systems endowed with high spatial and temporal resolution allows for studies with a higher degree of detail. Consequently, remote-sensing systems (mainly lidar) become an important tool in ABLH detection (Martucci et al., 2007; Pal et al., 2010; Wang et al., 2012), as well as in turbulence studies (Lagouarde et al., 2013, 2015). In addition, the different lidar techniques offer the possibility of analyses with several variables, such as vertical wind velocity by Doppler lidar (Lenschow et al., 2000; Lothon et al., 2006; O'Connor et al., 2010), water vapor mixing profiles by Raman lidar or differential absorption lidar (DIAL) (Wulfmeyer, 1999; Kiemle et al., 2007; Wulfmeyer et al., 2010; Turner et al., 2014; Muppa et al., 2016), temperature by rotational Raman lidar (Hammann et al., 2015), and aerosol number density by elastic lidar or high spectral resolution lidar (HSRL) (Pal et al., 2010; McNicholas and Turner, 2014). Therefore, a wider range of results can be obtained, especially when different types of systems are synergistically used, as shown by Engelmann et al. (2008), who combine elastic and Doppler lidar data for deriving the vertical aerosol flux.

Pal et al. (2010) have shown that it is feasible to use elastic lidar measuring at a high acquisition rate for characterizing the atmospheric turbulence. In particular, they have shown that the fluctuation of the range-corrected signal (RCS) at $1064 \mathrm{~nm}$ is a proxy for the fluctuation of the particle concentration, due to predominance of particle signature $\left(\beta_{\mathrm{par}}\right)$ in the total backscattered signal at this wavelength, and thus it can be used for observing the turbulent aerosol movements in the CBL. However, if other wavelengths are used in this kind of analysis, the effects of molecular backscatter coefficient $\left(\beta_{\mathrm{mol}}\right)$ and atmospheric extinction $(\alpha)$ must be considered. In this work, we perform a comparative analysis regarding the use of three different wavelengths, namely 355, 532 and $1064 \mathrm{~nm}$ (the latter adopted as reference), to obtain the high-order moments, i.e., variance $\left(\sigma^{2}\right)$, skewness $(S)$, kurtosis $(K)$ and also the integral timescale $(\tau)$. Moreover, the interference of noise $\varepsilon$ and $\beta_{\text {mol }}$ over the high-order moments and $\tau$ obtained from each one of the considered wavelengths was analyzed, in order to quantify how such factors can influence the correct interpretation of the statistical variables. The goal of this study is to show the viability of the proposed methodology for studying turbulence by computing the high-order moments of the backscattered signal at different wavelengths. We pay special attention to the advantages and limitations of each wavelength analyzed considering the importance of the proposed correction schemes. This paper is organized as follows. The measurement site and the experimental setup are introduced in Sect. 2. The methodology is described in Sect. 3. The comparisons and case studies are analyzed in Sect. 4. Conclusions are given in Sect. 5.

\section{Experimental site and instrumentation}

This study was performed at LEAL (Laser Environmental Applications Laboratory) from July 2017 to July 2018; however, to illustrate the analysis, only two cases are discussed in detail in this article. LEAL is part of the Latin America Lidar Network - (Guerrero-Rascado et al., 2016; Antuña Marrero et al., 2017) since 2001. This lidar facility is installed at the Nuclear and Energy Research Institute in São Paulo, Brazil $\left(23^{\circ} 33^{\prime} \mathrm{S}, 46^{\circ} 38^{\prime} \mathrm{W}, 760 \mathrm{~m}\right.$ a.s.1.), in the largest metropolitan area in South America, with a population of approximately 12 million and endowed with a subtropical climate where winter is mild $\left(15^{\circ} \mathrm{C}\right)$ and dry, while summer is wet and has moderately high temperatures $\left(23^{\circ} \mathrm{C}\right)$ (IBGE, 2017). The São Paulo lidar station (SPU) has a coaxial ground-based multiwavelength Raman lidar system operated at LEAL. The system operates with a pulsed $\mathrm{Nd}$ : YAG laser, emitting radiation at 355,532 , and $1064 \mathrm{~nm}$; a laser repetition rate of $10 \mathrm{~Hz}$; and a laser beam pointing to zenith direction. The pulse energy (and stability) of each wavelength is $225 \mathrm{~mJ}$ $(2 \mathrm{~mJ})$ at $355 \mathrm{~nm}, 400 \mathrm{~mJ}(4 \mathrm{~mJ})$ at $532 \mathrm{~nm}$ and $850 \mathrm{~mJ}(6 \mathrm{~mJ})$ at $1064 \mathrm{~nm}$. The Metropolitan São Paulo I (MSPI) lidar detects three elastic channels at 355, 532 and $1064 \mathrm{~nm}$ and three Raman-shifted channels at $387 \mathrm{~nm}, 408 \mathrm{~nm}$ (corresponding to the shifting from $355 \mathrm{~nm}$ by $\mathrm{N}_{2}$ and $\mathrm{H}_{2} \mathrm{O}$ ) and $530 \mathrm{~nm}$ (corresponding to the rotational Raman shifting from $532 \mathrm{~nm}$ by $\mathrm{N}_{2}$, Veselovskii et al., 2015). This system is equipped with Hamamatsu R7400 photomultipliers . The SPU lidar reaches full overlap at around $300 \mathrm{~m}$ a.g.1. (Lopes et al., 2018). This system operates with temporal and spatial resolution of $2 \mathrm{~s}$ and $7.5 \mathrm{~m}$, respectively. 


\section{Methodology}

The turbulence study is based on the observation of the fluctuation $q^{\prime}(t)$ of a determined variable $(q)$ in the time $t$. The values are obtained as follows: firstly $q(t)$ are averaged in packages that cover a certain time interval, from which the mean value $(\bar{q})$ is extracted. Then, such values are subtracted from each $q(t)$ value, providing the fluctuation $q^{\prime}(t)$ as demonstrated in the equation below via Reynolds decomposition (de Arruda Moreira et al., 2019):

$q^{\prime}(t)=q(t)-\bar{q}(t)$.

In the analysis performed with elastic lidar systems, the variable of interest is the aerosol number density $(N)$, from which we obtain its fluctuation $\left(N^{\prime}\right)$ by Eq. (1). However, elastic lidar systems do not directly provide the value of $N$. Therefore, considering the validity of Mie theory (where the aerosol backscatter coefficient is linked to the backscatter efficiency, particle radius $(r)$ and the number of particles with radius $r$ ), we can write Eq. (2) under several assumptions. The premises adopted here are that (i) the variation in aerosol size with the relative humidity can be neglected, (ii) the atmospheric volume probed is composed of similar types of aerosol particles and (iii) the fluctuations of the aerosol microphysical properties are smaller than the fluctuations of the total number density in the volume probed by the lidar. More details about these assumptions can be found in Pal et al. (2010). Feingold and Morley (2003) and Titos et al. (2016) demonstrated the relation between relative humidity and hygroscopic growth, thus such effects can start at $80 \% \mathrm{RH}$. The two cases presented in this work were gathered in winter, the driest season of São Paulo. In particular, RH was below $80 \%$ in both days (see Sect. 4). Such a value is lower than the RH threshold to hygroscopic effects indicated by the two papers mentioned above. Consequently, ignoring the hygroscopic growth and assuming similar types of aerosol throughout the atmospheric column, the following equation can be used:

$\beta_{\text {aer }}(z, t) \approx N(z, t) Y(z)$,

$\beta^{\prime}{ }_{\text {aer }}(z, t)=N^{\prime}(z, t)$,

where $\beta_{\text {aer }}$ and $\beta^{\prime}$ aer represent the particle backscatter coefficient and its fluctuation, respectively. The variable $z$ is the height above the ground, $t$ is the time and $Y$ is a variable that does not depend on time.
The lidar equation is defined as follows in Weitkamp (2005):

$$
\begin{gathered}
P(z, t)=P_{0} \frac{c \tau}{2} A \eta O(\lambda, z) \frac{\beta(\lambda, z)}{z^{2}} \\
\exp \left[-2 \int_{o}^{z} \alpha\left(\lambda, z^{\prime}\right) \mathrm{d} z^{\prime}\right],
\end{gathered}
$$

where $P(\lambda, z)$ is the power signal (W) detected at a distance $z(\mathrm{~m})$ and time $t(\mathrm{~s}), z$ is the distance $(\mathrm{m})$ of the atmospheric volume investigated, $P_{0}$ is the power emitted by the laser source (W), $c$ is the speed of light $\left(\mathrm{m} \mathrm{s}^{-1}\right), \tau$ the laser pulse duration (ns), $A$ is the effective area of the telescope receptor $\left(\mathrm{m}^{2}\right), \eta$ is a variable related to the efficiency of the lidar system and $O(\lambda, z)$ is the laser beam receiver field-of-view overlap function. The most important quantities are $\beta(\lambda, z)$, which is the total backscatter coefficient, due to atmospheric molecules, $\beta_{\mathrm{mol}}(\lambda, z)$ and aerosol $\beta_{\mathrm{aer}}(\lambda, z)$. In other words, $\beta(\lambda, z)=\beta_{\mathrm{mol}}(\lambda, z)+\beta_{\mathrm{aer}}(\lambda, z)(\mathrm{m} \mathrm{sr})^{-1}$ at distance $z$ and $\alpha(\lambda, z)$ is the total extinction coefficient, due to atmospheric molecules, $\alpha_{\text {mol }}(\lambda, z)$ and aerosols $\alpha_{\text {aer }}(\lambda, z)$. In other words, $\alpha(\lambda, z)=\alpha_{\mathrm{mol}}(\lambda, z)+\alpha_{\text {aer }}(\lambda, z)(\mathrm{m})^{-1}$ at distance $z$. If the wavelength $1064 \mathrm{~nm}$ is used, we can neglect the influence of the extinction coefficient $\alpha(\lambda, z)$ provided by aerosol, the Rayleigh scattering generated by atmospheric molecules and the $\beta_{\mathrm{mol}}(\lambda, z)$ (Pal et al., 2010). Therefore, Eq. (4) for the wavelength of $1064 \mathrm{~nm}$ can be rewritten as follows:

$$
\begin{aligned}
& \operatorname{RCS}_{1064}(z, t)=P_{1064}(z, t) \cdot z^{2} \\
& \quad \approx G \cdot \beta_{1064}(z, t) \approx G \cdot \beta_{\text {aer }}(z, t),
\end{aligned}
$$

where $\mathrm{RCS}_{1064}$ is the range-corrected signal, $G$ is a constant and the subscribed indexes represent the wavelength and the particles. Then, by applying Reynolds decomposition (Eq. 1) over Eq. (5), the following equation is derived as follows:

$\operatorname{RCS}_{1064}{ }^{\prime}(z, t) \approx \beta_{1064}{ }^{\prime}(z, t)=\beta_{\text {aer }}{ }^{\prime}(z, t)=N^{\prime}(z, t)$.

Our purpose is to evaluate the use of other wavelengths under the effects of the molecular backscatter coefficient $\left(\beta_{\mathrm{mol}}\right)$. The interest is based on the best performance of the technology for detecting wavelengths in the VIS and UV and on the extended use of these wavelengths in the following lidar networks: the Latin America Lidar Network - LALINET (Guerrero-Rascado et al., 2016; Antuña Marrero et al., 2017), European Aerosol Research Lidar Network - EARLINET (Pappalardo et al., 2014) and the NASA Micropulse Lidar Network - MPLNet (Welton et al., 2001).

\subsection{High-order moments}

The high-order moments used in this study are obtained from $\operatorname{RCS}^{\prime}(z, t)$, generated by Eq. (1), where $\overline{\operatorname{RCS}}(z)$ represents the $1 \mathrm{~h}$ average package of $\operatorname{RCS}(z, t)$ data. From this, the high-order moments, variance $\left(\sigma^{2}\right)$, skewness $(S)$ and kurtosis $(K)$ are obtained as demonstrated in the first column of 
Table 1, as well as their corrections and errors in the second and third columns of the same table, respectively. In Table 2 the physical meaning of each high-order moment in the context of the proposed analysis is presented.

The integral timescale $(\tau)$ is an important prerequisite in turbulence studies. It guarantees that most of the horizontal variability of the turbulent eddies is detected with good resolution, enabling the solution of inertial subrange and dissipation range in the spectrum and autocorrelation function, respectively (Pal et al., 2010). $\tau$ must be larger than the temporal resolution of the analyzed time series (SPU lidar station time acquisition is $2 \mathrm{~s}$ ). In the same way as the highorder moments, such variables are obtained from $\operatorname{RCS}^{\prime}(z, t)$, as shown in the first column of Table 1.

\subsection{Error analysis}

The high-order moments and $\tau$ generated from $\operatorname{RCS}^{\prime}(z, t)$ can also be obtained from the following autocovariance function $M_{i j}$, which has its order represented by the sum of the subscript $i$ and $j$ (Pal et al., 2010), according to the following equation:

$M_{i j}=\int_{0}^{t_{\mathrm{f}}}\left[\operatorname{RCS}^{\prime}(z, t)\right]^{i}\left[\operatorname{RCS}^{\prime}\left(z, t+t_{\mathrm{f}}\right)\right]^{j} \mathrm{~d} t$,

where $t_{\mathrm{f}}$ means final time. However, it is important to consider the influence of instrument noise $\varepsilon(z, t)$ in the $\operatorname{RCS}^{\prime}(z, t)$ profile. Therefore, $M_{i j}$ can be rewritten as follows:

$$
\begin{gathered}
M_{i j}=\int_{0}^{t_{\mathrm{f}}}\left[\operatorname{RCS}^{\prime}(z, t)+\varepsilon(z, t)\right]^{i} \\
\left.\operatorname{RCS}^{\prime}\left(z, t+t_{\mathrm{f}}\right)+\varepsilon\left(z, t+t_{\mathrm{f}}\right)\right]^{j} \mathrm{~d} t .
\end{gathered}
$$

Although atmospheric fluctuations are correlated in time, $\varepsilon(z, t)$ is random and uncorrelated with the atmospheric signal; therefore, $\varepsilon(z, t)$ is only associated with lag zero. Consequently, it is possible to obtain the corrected autocovariance function, $M_{11}(\rightarrow 0)$, removing the error $\Delta M_{11}(0)$ of the uncorrected autocovariance function $M_{11}(0)$, as demonstrated in the equation below:

$M_{11}(\rightarrow 0)=M_{11}(0)-\Delta M_{11}(0)$.

Based on this concept, Lenschow et al. (2000) proposed two methods to correct for the noise influence:

- First lag correction: the lag zero $\left(\Delta M_{11}(0)\right)$ is directly subtracted from the uncorrected autocovariance function $M_{11}(0)$, generating $M_{11}(\rightarrow 0)$.

- Two-thirds correction: a new lag zero value is obtained by the extrapolation of $M_{11}(0)$ to the first nonzero lag

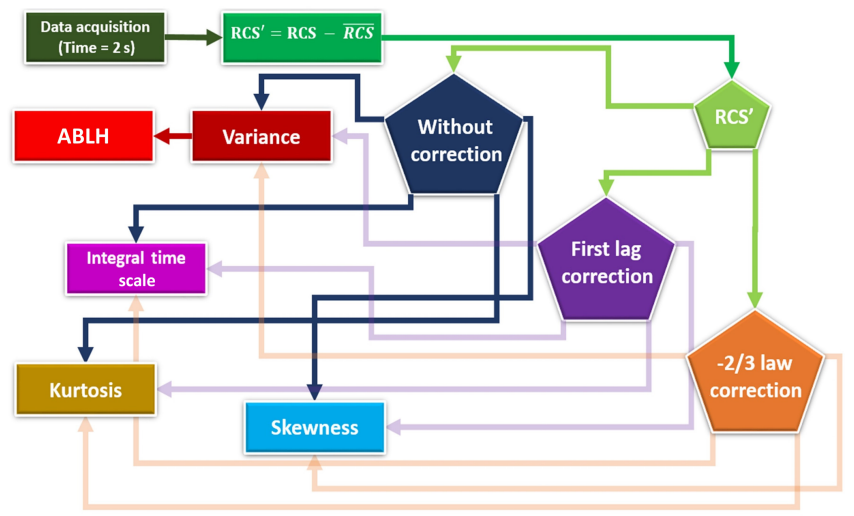

Figure 1. Methodological description of data analysis performed for elastic lidar data.

back to lag zero, using the inertial subrange hypothesis (Monin and Yaglom, 1979):

$$
M_{11}(\rightarrow 0)=\overline{R C S^{\prime}(z, t)}+C t^{2 / 3},
$$

where $C$ represents a parameter of turbulent eddy dissipation rate. In this study, we also used the first five points after lag zero to perform this correction. In Table 1 the second and third columns present the corrections and errors, respectively, of high-order moments and $\tau$.

Figure 1 shows how the procedures described in Sect. 3.1 and 3.2 are used. Firstly, the lidar data are acquired with a time resolution of $2 \mathrm{~s}$. Then, these data are averaged in packages of $1 \mathrm{~h}$ (the influence of the time window is demonstrated in de Arruda Moreira et al., 2019) generating $\overline{\operatorname{RCS}(z)}$, from which it is possible to obtain $\operatorname{RCS}^{\prime}(z, t)$, as illustrated in Eq. (1). Then, the two corrections shown in Sect. 3.2 are separately applied. Finally, the high-order moments and the $\tau$, corrected and without correction, are estimated. The ABLH is estimated from the variance method, which establishes, in convective conditions, the top of CBL (ABLH) as the maximum of the variance of the RCS $\left[\sigma_{\mathrm{RCS}}^{2}(z)\right]$ (Baars et al., 2008). Examples of the application of such a methodology in varied meteorological scenarios (presence of clouds and aerosol sublayers) are presented in de Arruda Moreira et al. (2019).

\section{Results}

In this section we present two case studies, applying the methodology described in Sect. 3, in order to perform a comparative analysis about the influence of $\beta_{\mathrm{mol}}$ and $\varepsilon$ in the high-order moments and $\tau$ obtained from different wavelengths (355, 532 and $1064 \mathrm{~nm})$. 
Table 1. Variables applied to statistical analysis of turbulence in the ABL region (Lenschow et al., 2000). The sum of subindex of autocovariance function $M_{i j}$ represents the order of the analysis.

\begin{tabular}{llll}
\hline & $\begin{array}{l}\text { Without } \\
\text { correction }\end{array}$ & Correction & Error \\
\hline $\begin{array}{l}\text { Integral } \\
\text { timescale } \\
(\tau)\end{array}$ & $\int_{0}^{\infty} \operatorname{RCS}^{\prime}(t) \mathrm{d} t$ & $\frac{1}{\overline{\mathrm{RCS}^{\prime 2}} \int_{t \rightarrow 0}^{\infty} M_{11}(t) \mathrm{d} t}$ & $\tau \sqrt{\frac{4 \Delta M_{11}}{M_{11}(\rightarrow 0)}}$ \\
\hline $\begin{array}{l}\text { Variance } \\
\left(\sigma_{\mathrm{RCS}}^{2}\right)\end{array}$ & $\frac{1}{T} \sum_{t=1}^{T}\left(\mathrm{RCS}^{\prime}(t)-\overline{\mathrm{RCS}^{\prime}}\right)^{2}$ & $M_{11}(\rightarrow 0)$ & $\mathrm{RCS}^{\prime 2} \sqrt{\frac{4 \Delta M_{11}}{M_{11} \rightarrow 0}}$ \\
\hline Skewness $(S)$ & $\frac{\mathrm{RCS}^{3}}{\sigma_{\mathrm{RCS}^{\prime}}^{3}}$ & $\frac{M_{21}(\rightarrow 0)}{M_{11}^{3 / 2}(\rightarrow 0)}$ & $\frac{\Delta M_{21}}{\Delta M_{11}^{3 / 2}}$ \\
\hline$\frac{\mathrm{RCS}^{4}}{\sigma_{\mathrm{RCS}^{\prime}}^{4}}$ & $\frac{3 M_{22}(\rightarrow 0)-2 M_{31}(\rightarrow 0)-3 \Delta M_{11}^{2}}{M_{11}^{2}(\rightarrow 0)}$ & $\frac{4 \Delta M_{31}-3 \Delta M_{22}-\Delta M_{11}^{2}}{\Delta M_{11}^{2}}$ \\
\hline
\end{tabular}

Table 2. Physical meaning of the high-order moments

\begin{tabular}{ll}
\hline $\begin{array}{l}\text { Integral } \\
\text { timescale } \\
(\tau)\end{array}$ & Physical meaning \\
\hline $\begin{array}{l}\text { Variance } \\
\left(\sigma_{\mathrm{RCS}}^{2}\right)\end{array}$ & It represents the time over which the turbulent process are highly correlated to itself. \\
\hline Skewness $(S)$ & $\begin{array}{l}\text { It represents a measure of the lack of symmetry of a distribution. The values close to zero } \\
\text { indicates that the aerosol particles are evenly distributed. Negative values indicate entrainment } \\
\text { of clean FT air into the ABL, which causes negative perturbations. On the other hand, the } \\
\text { positive values are associated with the center of the aerosol plumes that are penetrating at a } \\
\text { determined height. }\end{array}$ \\
\hline Kurtosis $(K)$ & $\begin{array}{l}\text { It represents a measure of the flatness of a distribution. Values lower than } 3 \text { represents a time } \\
\text { series clustered around a mean value; therefore, characterizing a well-mixed ABL region. On } \\
\text { the other hand, values higher than } 3 \text { indicate the presence of infrequent deviations in the time } \\
\text { series, representing a region with a low level of mixing. }\end{array}$ \\
\hline
\end{tabular}

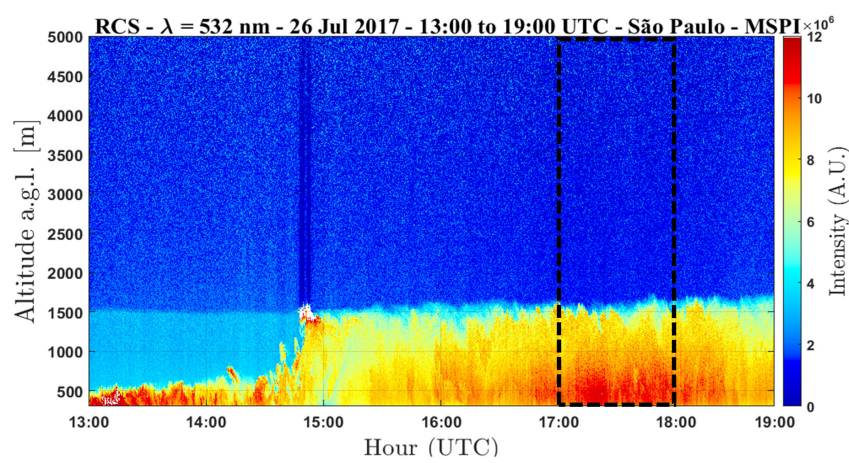

Figure 2. Time-height plot of $\mathrm{RCS}_{532}$.

\subsection{Case study I: 26 July 2017}

In this case study we gathered measurements from 13:00 to 19:00 UTC. Figure 2 shows the time-height plot of $\mathrm{RCS}_{532}$ during this period. This case is composed of two distinct periods, in the first $2 \mathrm{~h}$ there is an RL with an underlying shallow CBL. Nevertheless, in the last part of the second hour the CBL quickly grows and it mixes with RL, forming a fully developed ABL, with its top situated between 1500 and $1600 \mathrm{~m}$ from 15:00 to 19:00 UTC. The dotted black box between 17:00 and 18:00 UTC represents the period selected to perform the statistical analysis.

In order to check the hypothesis proposed by Pal et al. (2010), which assumes that there is not particle hygroscopic growth and that the same type of aerosol is present in the entire atmospheric column in the $\mathrm{ABL}$ region, we analyzed the relative humidity and mixing ratio profile re- 

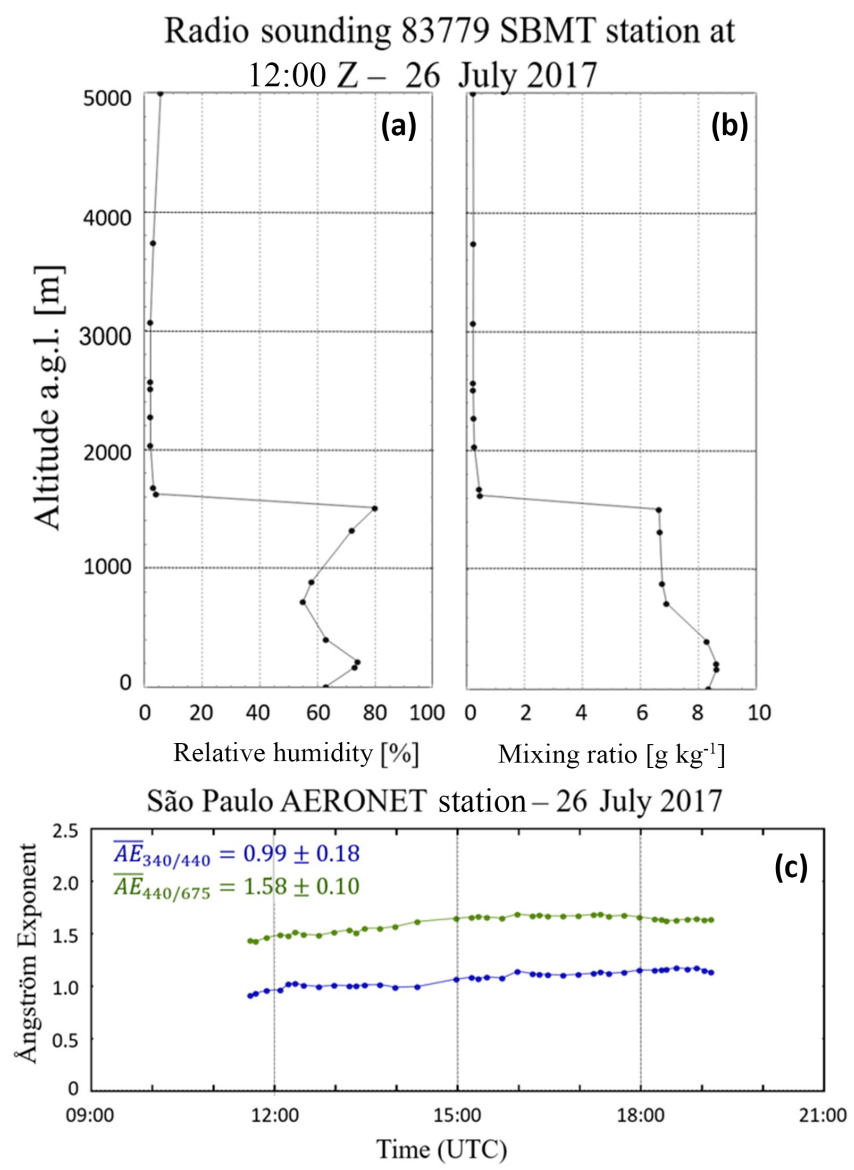

Figure 3. (a) Vertical profile of relative humidity derived from radio sounding. (b) Mixing ratio derived from radio sounding. (c) Aerosol-optical-depth-related Ångström exponent time series from AERONET, for measurements retrieved at 26 July 2017.

trieved from radio-sounding measurements (http://weather. uwyo.edu/upperair/sounding.html, last access: 25 September 2018), launched at the Campo de Marte Airport (São Paulo, Brazil), which is about $10 \mathrm{~km}$ away from the SPU lidar system. Figure $3 a$ and $b$ show the relative humidity and mixing ratio profiles, respectively, measured on $26 \mathrm{Jul} 2017$ at 12:00 UTC. Both relative humidity and mixing ratio can be considered constant below $1500 \mathrm{~m}$, with mean values of $67 \pm 8 \%$ and $7.6 \pm 0.9 \mathrm{~g} \mathrm{~kg}^{-1}$, respectively. Since there is no large variation in water vapor mixing ratio and relative humidity values in this region, we assume that this case is not affected by particle hygroscopic growth. In addition, the AERONET Sun photometer (Holben et al., 1998a) data from the São Paulo station were retrieved in order to check the aerosol type, as can be seen in Fig. 3c.

According to Eck et al. (1999), the Ångström exponent (AE) can be a useful tool for distinguishing different types of atmospheric aerosols. Figure $3 \mathrm{c}$ shows the aerosol AE time series for the case study of 26 July 2017 . The AE was calculated at the spectral range $340-440$ and $440-675 \mathrm{~nm}$ using

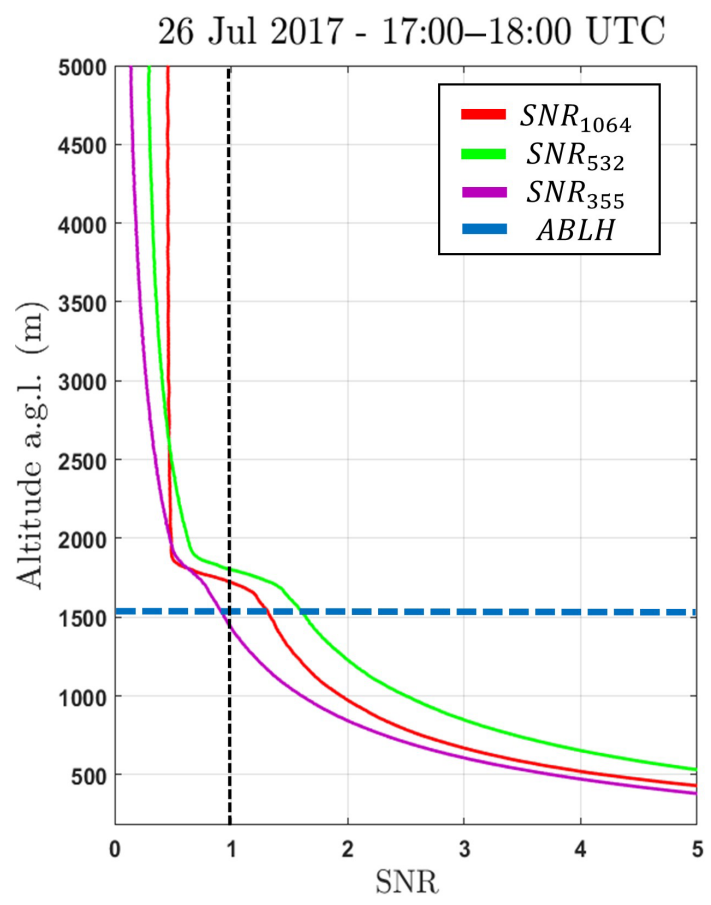

Figure 4. Signal-to-noise-ratio (SNR) profile of the three wavelengths (1064 nm, red line; $532 \mathrm{~nm}$, green line; and $355 \mathrm{~nm}$, violet line) obtained at 26 July 2017 between 17:00 and 18:00 UTC.

AERONET (Holben et al., 1998b) products from level 1.5 version 3 data. For this measurement period, the percentage variation in $\mathrm{AE}$ was no more than $3 \%$ in both cases. Therefore, there are no considerable changes during the whole measurement period, which is a strong indication that there is no aerosol type change throughout the day.

In Fig. 4 the signal-to-noise-ratio (SNR) profile of the raw lidar signal is presented, as calculated by Heese (2010) at three wavelengths $(1064 \mathrm{~nm}$, red line; $532 \mathrm{~nm}$, green line; and $355 \mathrm{~nm}$, violet line) during the analyzed period. All wavelengths have values of SNR higher than 1 (the threshold for good quality) below the ABLH (dotted blue line) with a predominance of values lower than 1 in the free troposphere (FT), which was expected due to the strong reduction of aerosol concentration in such region. Although the three wavelengths have similar SNR profiles, close to ABLH the differences among them become more evident, principally the fast decreasing of the $355 \mathrm{~nm}$ and the high values of $532 \mathrm{~nm}$.

Figure 5 shows the autocovariance function (ACF), obtained between 17:00 and 18:00 UTC for the wavelengths $355\left(\mathrm{ACF}_{355}\right), 532\left(\mathrm{ACF}_{532}\right)$ and $1064 \mathrm{~nm}\left(\mathrm{ACF}_{1064}\right)$ at 1000 and $1700 \mathrm{ma.g.l}$. Thus, from the comparison of Figs. 2 and 5 it is possible to observe that the altitude chosen at $1000 \mathrm{~m}$ (red line) is situated below the top of CBL, while the altitude chosen at $1700 \mathrm{~m}$ (light green line) is in the FT. As expected, the $\varepsilon$, which is represented by the peak on the lag zero of the autocovariance function (5), increases with 
height for all the wavelengths due to reduction of aerosol load with height. $\mathrm{ACF}_{355}$ has the lowest intensity (around $90 \%$ smaller those of $\mathrm{ACF}_{532}$ and $\mathrm{ACF}_{1064}$ ) and is clearly much more affected by the magnitude of $\varepsilon$ that represents approximately $25 \%$ of $\mathrm{ACF}_{355}$, while for $\mathrm{ACF}_{532}$ and $\mathrm{ACF}_{1064}$ the noise represents around $10 \%$ of the respective autocovariance.

Figure 6 presents all statistical variables, their respective corrections and errors (shadows), generated from the methodology described in Sect. 3 for data acquired between 17:00 and 18:00 UTC.

The variance profiles, $\sigma_{\mathrm{RCS}}^{2}(z)$, with and without corrections for all wavelengths are represented in Fig. 6.01.09 . The low and almost constant values of uncorrected $\sigma_{\mathrm{RCS}_{1064}}^{2}(z)$ from the bottom up to around $1000 \mathrm{~m}$ in altitude demonstrates an almost constant distribution of aerosol particles in this region, as can be seen in Fig. 6.01. Above $1000 \mathrm{~m}$ in altitude, the value of uncorrected $\sigma_{\mathrm{RCS}}^{2}{ }_{1064}(z)$ increases, reaching its maximum peak at around $1600 \mathrm{~m}$. This peak represents the entrainment zone, the region where a mixing occurs between air parcels coming from the CBL and FT. According to Menut et al. (1999), there is an intense variation in aerosol concentration during this process, generating a maximum in the uncorrected $\sigma_{\mathrm{RCS}}^{2}(z)$, which represents the ABLH. Above the ABLH, the aerosol concentration is considerably lower than in CBL and thus the uncorrected $\sigma_{\mathrm{RCS}_{1064}}^{2}(z)$ is reduced to practically zero. This methodology for estimating the ABLH is named the variance method or centroid method and it was described by Hooper and Eloranta (1986) and Menut et al. (1999), respectively. The main limitations of this method are its applicability only for CBL and the ambiguous results in complex cases, such as the presence of several aerosol layers (Emeis, 2011). In such situations more sophisticated methods like Wavelet (Pal et al., 2010), PathfinderTURB (Poltera et al., 2017) and POLARIS (Bravo-Aranda et al., 2017) are recommended.

The uncorrected $\sigma_{\mathrm{RCS}_{532}}^{2}(z)$, presented in Fig. 6.04, is rather similar to uncorrected $\sigma_{\mathrm{RCS}_{1064}}^{2}(z)$, including the position of maximum peak. Nevertheless, although uncorrected $\sigma_{\mathrm{RCS}_{355}}^{2}(z)$, presented in Fig. 6.07, also has the maximum peak situated at around $1600 \mathrm{~m}$ in altitude, the profile is noisier than the profiles obtained from the other wavelengths and, therefore, it is not possible to identify the regions with uniform aerosol distribution as evidenced in uncorrected $\sigma_{\mathrm{RCS}_{1064}}^{2}(z)$. Although the $\sigma_{\mathrm{RCS}_{355}}^{2}(z)$ is noisier than another ones, there is a low difference among the ABLH estimated from the three different wavelengths (lower than $10 \%$ ).

The two-thirds correction, shown in Fig. 6.02, 6.05 and 6.08 , does not cause significant changes in the uncorrected profiles. On the other hand, the first lag correction significantly changes the profiles, thus $\sigma_{\mathrm{RCS}}^{2}(z)$ becomes very similar to $\sigma_{\mathrm{RCS}}^{2}{ }_{1064}(z)$, while $\sigma_{\mathrm{RCS}}^{2}(z)$ continues with some differences, mainly in the region below the ABLH, as can be seen in Fig. 6.03, 6.06 and 6.09.
The integral timescale profiles $\tau_{\mathrm{RCS}^{\prime}}(z)$, with and without corrections, $\tau_{\mathrm{RCS}^{\prime}}^{\text {corr }}(z)$ and $\tau_{\mathrm{RCS}^{\prime}}^{\mathrm{unc}}(z)$, respectively, calculated for the three wavelengths are presented in Fig. 6.10.18. The $\tau_{\mathrm{RCS}^{\prime}}^{\mathrm{unc}}(z)$ presents values larger than SPU lidar station time acquisition, shown as a dotted black line in the region below $\mathrm{ABLH}$ at all wavelengths, as can be seen in Fig. 6.10, 6.13 and 6.16. The largest values of $\tau_{\mathrm{RCS}^{\prime}}^{\mathrm{unc}}(z)$ correspond to $1064 \mathrm{~nm}$, while the lowest values are computed for 355 , which is practically half of those obtained with the reference wavelength, $1064 \mathrm{~nm}$. The low value for the $\tau_{\mathrm{RCS}^{\prime}}^{\mathrm{unc}}(z)$ at $355 \mathrm{~nm}$ can be associated with the influence of the noise in the signal retrieved at this wavelength. The application of the two-thirds correction does not cause significant changes in the profiles, while the first lag correction changes the profiles significantly mainly in the region below the ABLH, as can be seen in Fig. 6.11, 6.14 and 6.17 and in Fig. 6.12, 6.15 and 6.18 , respectively.

The skewness profiles $S_{\mathrm{RCS}}(z)$ represent the degree of asymmetry in a distribution, where $S_{\mathrm{RCS}}(z)=0$ represents symmetric distributions around its mean, while positive and negative values represent cases where the tail of distribution is on the left and right side of the distribution, respectively. The uncorrected skewness profiles $S_{\mathrm{RCS}}^{\mathrm{unc}}(z)$ and their respective corrections $S_{\mathrm{RCS}}^{\mathrm{corr}}(z)$ for the three wavelengths are presented in Fig. 6.19-.27. The $S_{\mathrm{RCS}}^{\mathrm{unc}}(z)$ generated from the wavelengths 1064 and $532 \mathrm{~nm}$, presented in Fig. 6.19 and 6.22 , respectively, presents similar behavior up to approximately $150 \mathrm{~m}$ above the $\mathrm{ABLH}_{\text {elastic }}$, with positive values in the low part of the profile and one inflection point

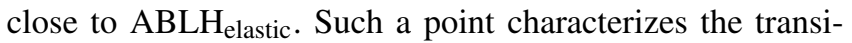
tion from the region with entrainment of clean FT air into the CBL (negative values) to a region a few meters above the $\mathrm{ABLH}_{\text {elastic }}$ with the presence of aerosol plumes (positive values) due to convective movement. This behavior of the skewness profile was also observed by Pal et al. (2010) and McNicholas and Turner (2014) at the region of the

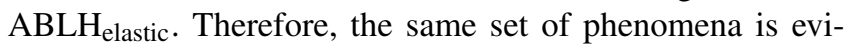
denced by the dataset at both wavelengths, although there are differences in the absolute values.

The two corrections cause negligible variations in the profiles at $1064 \mathrm{~nm}$, as shown in Fig. 6.20 and 6.21. On the other hand, the corrections applied to the $S_{\mathrm{RCS}}^{\mathrm{unc}}(z)$ at $532 \mathrm{~nm}$ produce skewness profiles similar to those at the reference wavelength, as can be seen in Fig. 6.23 and 6.24. It is possible to observe a difference between the skewness profiles at $532 \mathrm{~nm}$ (positive) and $1064 \mathrm{~nm}$ (negative) in the region above

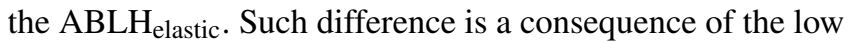
values of signal-to-noise ratio (SNR) of the RCS' and consequently $\tau_{\mathrm{RCS}}(z)$ observed in this region, preventing the observation of turbulence due to the technical limitations of the instruments used. The skewness profiles at $355 \mathrm{~nm}, S_{\mathrm{RCS}}^{\text {corr }}(z)$ and $S_{\mathrm{RCS}}^{\mathrm{unc}}(z)$ present a rather different behavior and do not follow the same variations observed in the reference wavelength profile, as can be seen in Fig. 6.25, 6.26 (two-thirds correction) and 6.27 (first lag correction). Consequently, it is 


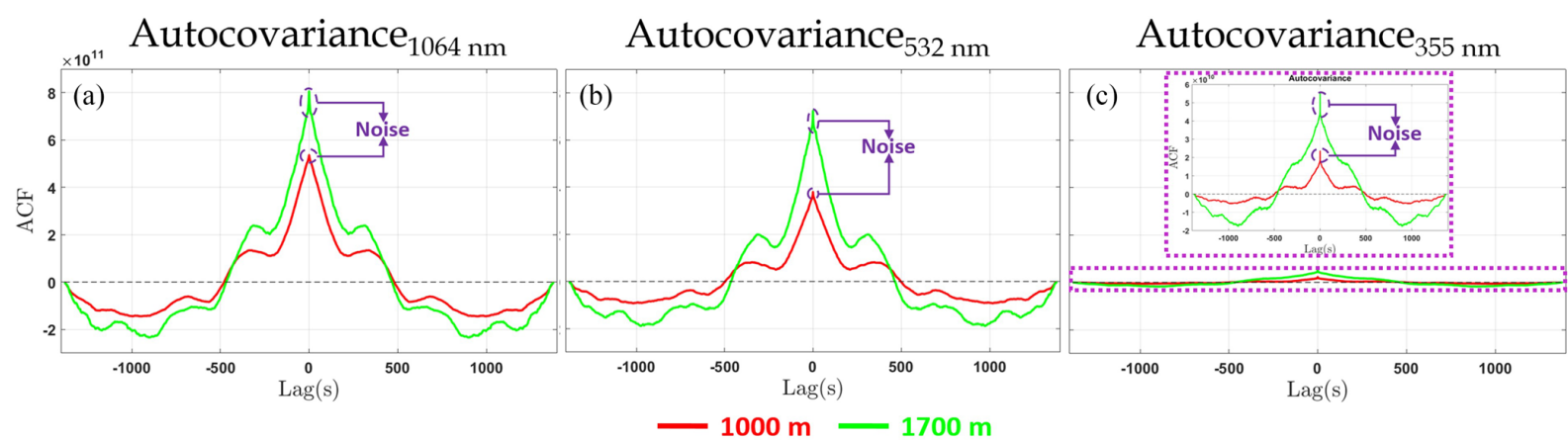

Figure 5. Autocovariance function at $1064 \mathrm{~nm}$ (a), $532 \mathrm{~nm}$ (b) and $355 \mathrm{~nm}$ (c) on 26 July 2017 from 17:00 to 18:00 UTC. For 355 nm the insert magnifies the signal 10x.

not possible to observe the aerosol dynamics using the information gathered at the wavelength $355 \mathrm{~nm}$.

The kurtosis profile $K_{\mathrm{RCS}^{\prime}}$ is the most complex high-order moment presented in this study and, consequently, in such profiles the differences among the three wavelengths are more evident. In the context of our analysis, the values of $K_{\mathrm{RCS}}$ are indicators of the mixing degree at each altitude, as well as of the intermittence of turbulence caused by large eddies. Because of some technical limitations of our lidar system, it is possible to resolve eddies only up to a predetermined size. Therefore, in regions where turbulence is performed in overly small scales, our system cannot solve these eddies. The kurtosis equation presented in the Table A1 represents the kurtosis of a normal distribution, which is equal to 3 (Bulmer, 1965). Consequently, such a value is applied as a threshold in the analyses performed in this paper. Values lower than 3 represent a well-mixed region, indicating a flatter distribution in comparison to a normal distribution, thus the turbulence caused by large eddies can be characterized as frequent. In contrast, values higher than 3 indicate a peaked distribution in comparison to a Gaussian distribution. In other words, there is an unusual variation in the $\operatorname{RCS}^{\prime}(z, t)$, which represents a low degree of mixing and the presence of an infrequent large eddy turbulence (Pal et al., 2010).

The $K_{\mathrm{RCS}}^{\mathrm{unc}}$ at 532 and $1064 \mathrm{~nm}$ have some differences in the region below $1300 \mathrm{~m}$ in altitude, where the profile at $1064 \mathrm{~nm}$ only shows values higher than 3 , representing a region with a low degree of mixing, while the $K_{\mathrm{RCS}}^{\mathrm{unc}}$ obtained from $532 \mathrm{~nm}$ is composed of values higher and lower than 3 . From 1300 to $3500 \mathrm{~m}$ in altitude, the profiles of these two wavelengths are very similar, with values lower than 3 in the region below the ABLH, characterizing a well-mixed region, a peak of values higher than 3 in the first meters above the $\mathrm{ABLH}$, and values between 3 and 4 in the remainder of the profile. The corrections do not cause significant changes in the $1064 \mathrm{~nm}$ kurtosis profile, as can be seen in Fig. 6.29 and 6.30. However, the variation in the kurtosis profile at $532 \mathrm{~nm}$ is remarkable, as presented in Fig. 6.32 and 6.33. Thus, it becomes very similar to the $1064 \mathrm{~nm}$ profile, mainly with the use of first lag correction. The $K_{\mathrm{RCS}^{\prime}}^{\mathrm{unc}}$ obtained from $355 \mathrm{~nm}$ does not have the same variations observed in the profiles obtained at the reference wavelength. Therefore, it is not possible to identify the occurrence of the phenomena previously described. The same problem occurs in the $K_{\mathrm{RCS}^{\prime}}^{\text {corr }}$, although the application of corrections causes relevant variations in relation to values observed in $K_{\mathrm{RCS}^{\prime}}^{\mathrm{unc}}$.

Figure 7 shows the profiles of $\beta_{\mathrm{mol}}, \beta_{\mathrm{mol}+\text { aer }}$ and $\beta_{\text {ratio }}$ of the wavelengths $1064 \mathrm{~nm}$ (Fig. 7.1 and 7.2), $532 \mathrm{~nm}$ (Fig. 7.3 and 7.4) and $355 \mathrm{~nm}$ (Fig. 7.5 and 7.6). Such profiles were obtained from the data retrieved during the period of analysis presented previously. From Fig. 7.1 it is possible to observe the predominance of $\beta_{\text {aer }}$ in the wavelength $1064 \mathrm{~nm}$ and because of this the $\beta_{\text {ratio }}$ presented in Fig. 7.2 achieved large values. In Fig. 7.3 it is possible to observe the predominance of $\beta_{\text {aer }}$ in the wavelength $532 \mathrm{~nm}$ and a small impact of $\beta_{\text {mol }}$. The backscatter profile at $355 \mathrm{~nm}$ presented in Fig. 7.5 shows that both $\beta_{\text {aer }}$ and $\beta_{\mathrm{mol}}$, have the same order of magnitude but with a predominance of $\beta_{\text {aer }}$. Such profiles justify the differences and similarities observed in the results obtained from each wavelength. Although the backscatter profiles at $532 \mathrm{~nm}$ are composed of the molecular and aerosol signatures, the predominance of the latter enables the observation of the phenomena presented by high-order moment profiles obtained from the reference wavelength. The small presence of $\beta_{\mathrm{mol}}$ can also be an indicator of the low values of noise, although they are higher than the values of reference wavelength.

\subsection{Case study II: 19 July 2018}

In this case study measurements were gathered with the SPU lidar station from 12:00 to 21:00 UTC. Figure 8 shows the time-height plot of $\mathrm{RCS}_{532}$ during this period (the timeheight plot of the RCS 355 and $\mathrm{RCS}_{1064}$ are available in the Supplement as Figs. S1 and S2, respectively). At the beginning of measurement it is possible to observe the presence of an ascending CBL covered by a RL, which has the top situated at around $1300 \mathrm{~m}$ in altitude. At approximately 15:30 UTC the CBL breaks up the RL and becomes fully 

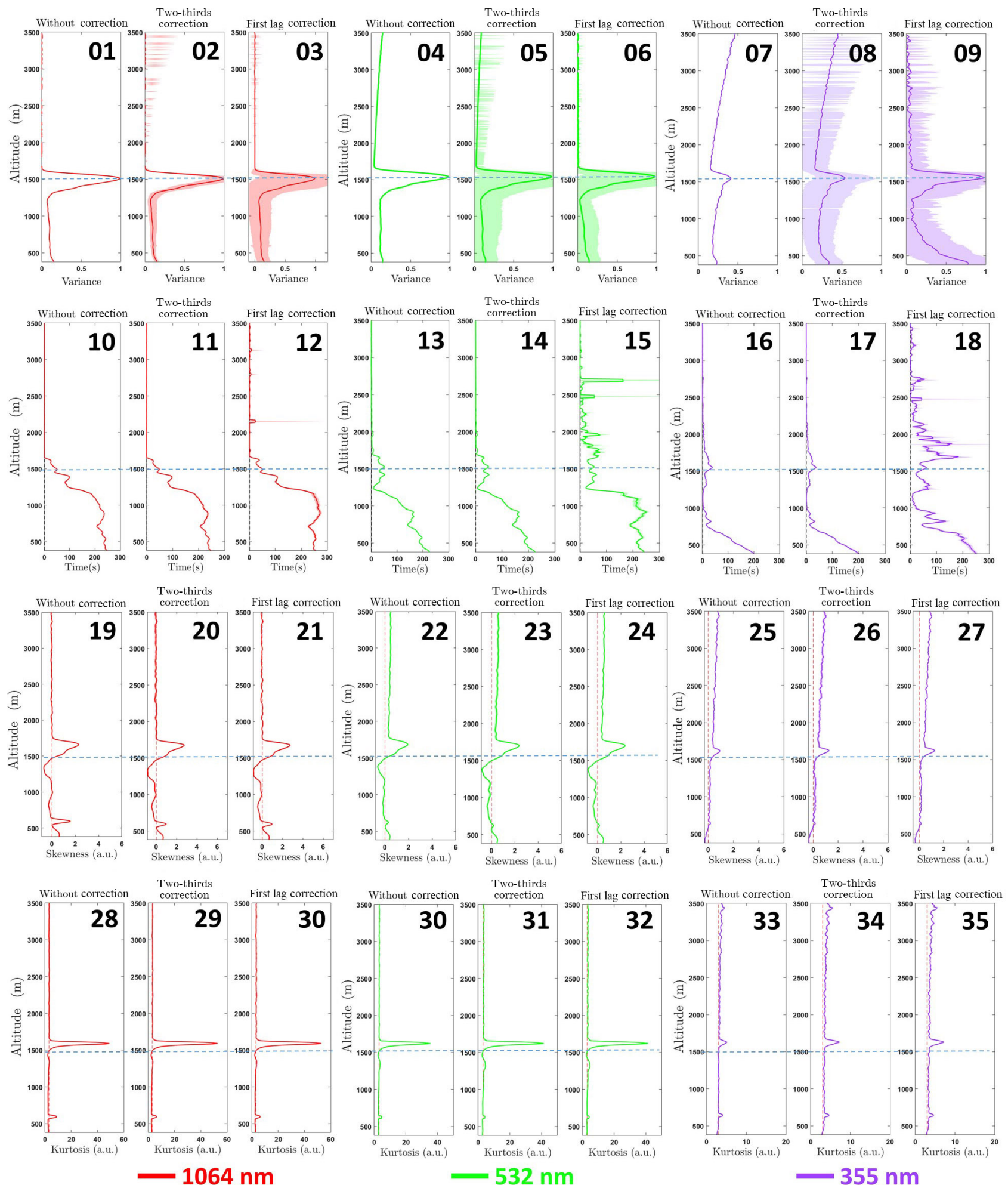

Figure 6. High-order moments and $\tau$ without correction and corrected by the two-thirds law and first lag correction at 1064 (red line), 532 (green line) and $355 \mathrm{~nm}$ (violet line) on 26 July 2017 from 17:00 to 18:00 UTC. The horizontal dotted blue line represents the ABLH $\mathrm{elastic}_{\text {. }}$ 
SPU station - São Paulo - 26 Jul 2017 - 17:00-18:00 UTC
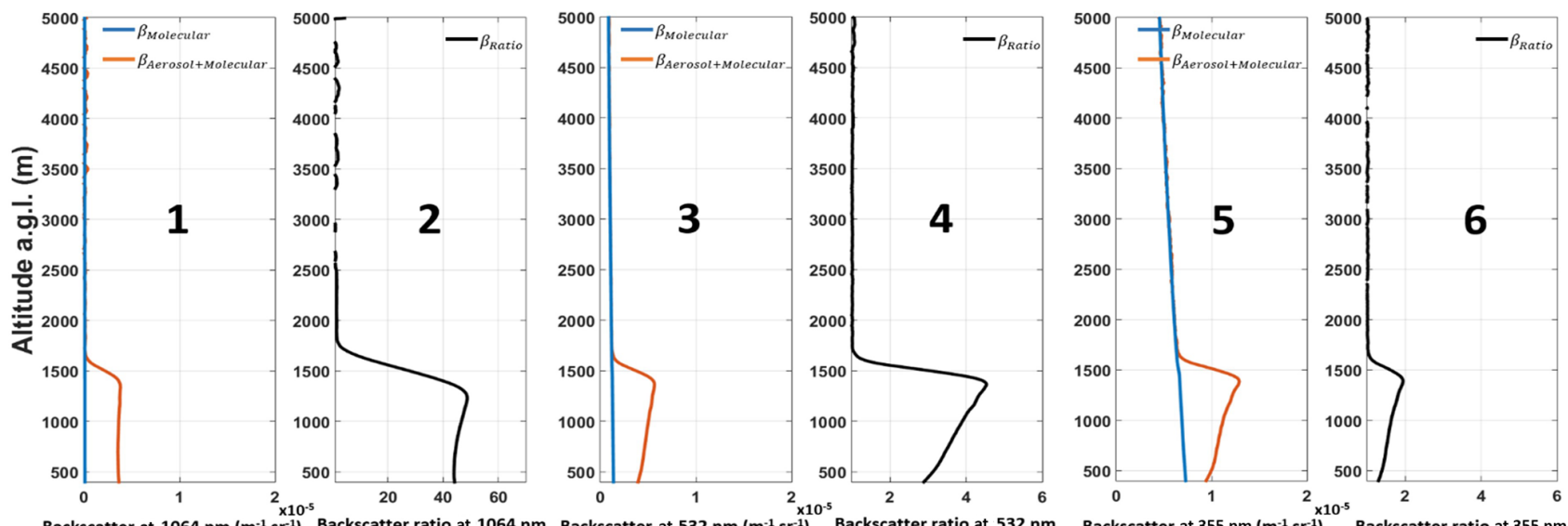

Figure 7. Total (aerosol and molecular) backscatter profile and backscatter ratio retrieved using the Klett-Fernald-Sasano inversion technique for 1064, 532 and $355 \mathrm{~nm}$, respectively, for data retrieved on 26 July 2017 at 17:00-18:00 UTC by the SPU lidar system.

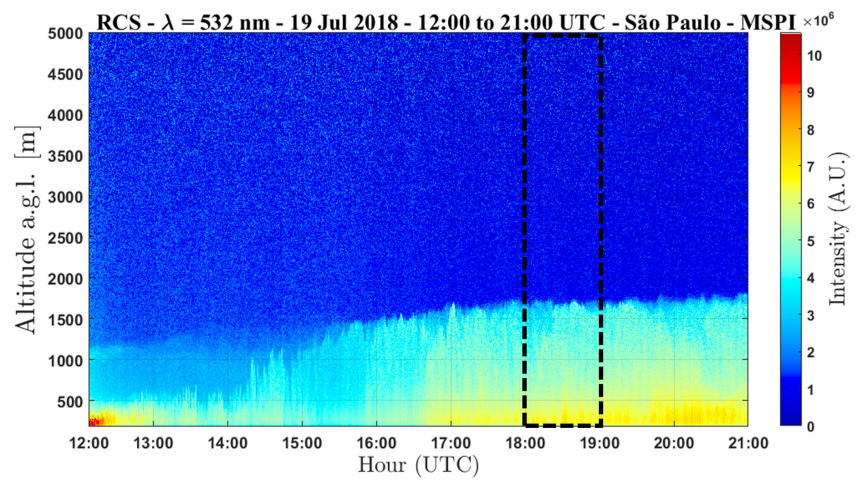

Figure 8. Time-height plot of $\operatorname{RCS}_{532}$.

developed, thus its growth speed is reduced and the value of top height remains practically constant $(1600 \mathrm{~m})$ from 17:00 UTC until 21:00 UTC. The dotted black box in Fig. 8 represents the chosen period for performing the statistical analysis (18:00-19:00 UTC).

In the same way as case study I, the hypothesis proposed by Pal et al. (2010) is validated from the profiles presented in Fig. 9 (more information are available in the Suplement as Fig. S3). The profiles of relative humidity and mixing ratio, presented in Fig. 9a and b, respectively, do not have large variations in the CBL below $1200 \mathrm{~m}$ in altitude. In addition, the aerosol-optical-depth-related Ångström exponent time series did not show considerable changes during the whole measurement period, as can be seen in Fig. 9c. For this measurement period the percentage variation in $\mathrm{AE}$ was no more than $4 \%$ and $3 \%$ in the spectral range 340-440 and $440-675 \mathrm{~nm}$, respectively. Therefore, there are no considerable changes during the whole measurement period, which is a strong indication that there are no aerosol type change throughout the day and the atmospheric conditions are not propitious for particle hygroscopic growth events.

Figure 10 presents the SNR profile of the raw lidar signal of the three wavelengths $(1064 \mathrm{~nm}$; red line; $532 \mathrm{~nm}$, green line; and $355 \mathrm{~nm}$, violet line) during the analyzed period. In the $\mathrm{ABL}$ region, all wavelengths have similar profiles with values higher than 1 . However, as ABLH approaches, the values of SNR reduce sharply, mainly at $355 \mathrm{~nm}$. Consequently, in the FT region all profiles have values lower than 1, as expected.

Figure 11 shows a comparison among the ACF obtained from the three wavelengths $1064 \mathrm{~nm}$ (Fig.11a), $532 \mathrm{~nm}$ (Fig.11b) and $355 \mathrm{~nm}$ (Fig.11c), between 18:00 and 19:00 UTC at two heights: $1000 \mathrm{~m}$ (red line) and 1700 (green line). In the same way as case study I, the region above ABLH (green line) is more influenced by noise than the region situated below this height (red line). The intensity of $\mathrm{ACF}_{532}$ and $\mathrm{ACF}_{1064}$ are very similar, although the presence of noise in the former, which is $40 \%$ and $46 \%$, below and above ABLH, respectively, is higher than in the latter, $27 \%$ and $30 \%$, below and above $\mathrm{ABLH}$, respectively. The $\mathrm{ACF}_{355}$ presents a lower intensity value in comparison to the other two wavelengths and a strong presence of noise below and above the ABLH, $50 \%$ and $67 \%$, respectively.

The three high-order moments and $\tau_{\text {RCS }}$, both corrected by the first lag correction and obtained between 18:00 and 19:00 UTC, are presented in Fig. 12. The $\tau_{\mathrm{RCS}}^{\text {corr }}$ for all wavelengths has values higher than $2 \mathrm{~s}$ from the bottom of profile up to the first meters above the $\mathrm{ABLH}_{\text {elastic }}$ with a maximum of $\sigma_{\mathrm{RCS}^{\prime}}^{2}(z)$. Although the values obtained from $1064 \mathrm{~nm}$ and $532 \mathrm{~nm}$ are almost twice as large as the values generated from $355 \mathrm{~nm}$ (in the same way as case study I), there are some differences among the maxima of the $\left[\sigma_{\mathrm{RCS}}^{2}(z)\right]$ and they do not significantly influence the ABLH estimation, thus the difference among the ABLH obtained from each wavelength is 
Radio sounding 83779 SBMT station at
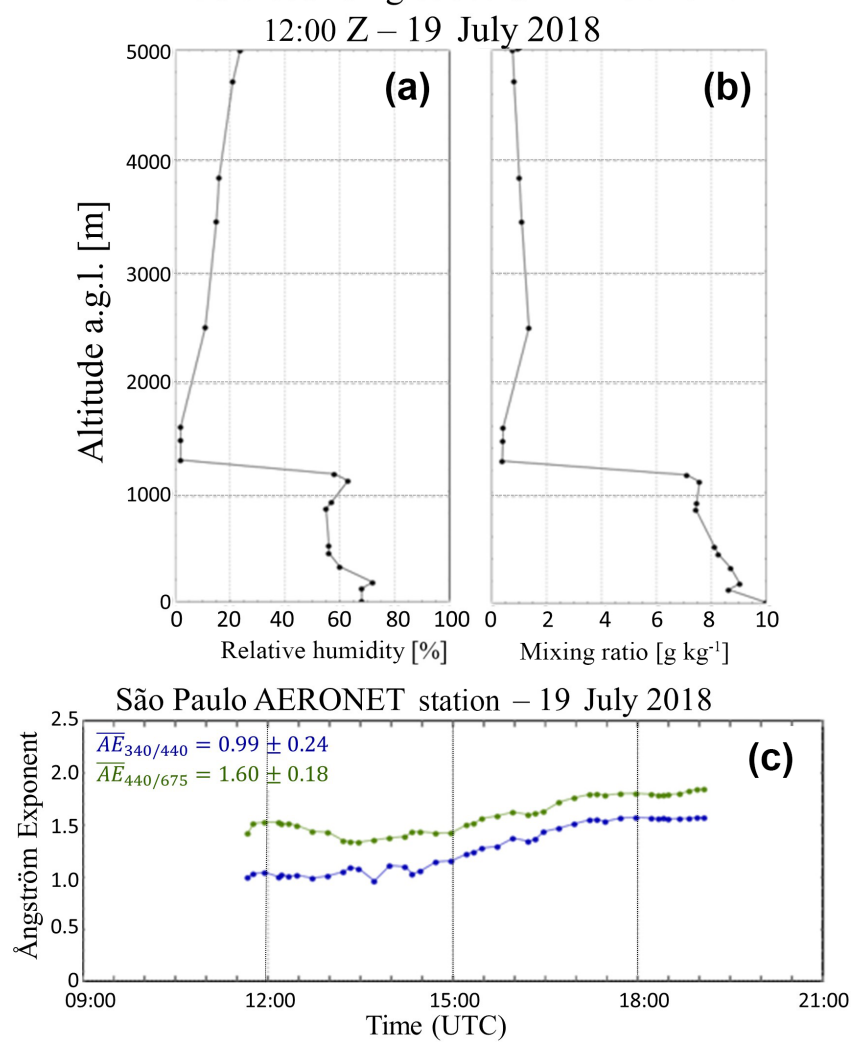

Figure 9. (a) Vertical profile of relative humidity derived from radio sounding. (b) Mixing ratio derived from radio sounding. (c) Aerosol-optical-depth-related Ångström exponent time series from AERONET, for measurements retrieved at 19 July 2018.

lower than $10 \%$. The positive values of $S_{\mathrm{RCS}}^{\text {corr }}(z)$ of $1064 \mathrm{~nm}$ indicate the presence of aerosol updrafts from the bottom of the profile up to around $750 \mathrm{~m}$ in altitude. From this height up to the ABLH, the $S_{\mathrm{RCS}}^{\mathrm{corr}}(z)$ is characterized by negative values, which represents a region with entrainment of clean FT air into the CBL. In the same way as case study I, there is an inflection point at ABLH, which reproduces the transition from negative to positive values, the latter values indicating the presence of aerosol updraft layers in the first $200 \mathrm{~m}$ above the ABLH. Such behavior in the region of ABLH was also observed by Pal et al. (2010) and McNicholas and Turner (2014) and can be considered characteristic of convective regime. The $S_{\mathrm{RCS}}^{\mathrm{corr}}(z)$ obtained from the wavelengths 1064 and $532 \mathrm{~nm}$ presents an identical pattern of behavior, demonstrating the occurrence of the same phenomena. The $S_{\mathrm{RCS}}^{\mathrm{corr}}(z)$ obtained from the wavelength $355 \mathrm{~nm}$, in the same way as the previous case study, does not exhibit the behavior observed in the reference wavelength, presenting only positive values in the whole profile. Therefore, it is not possible to identify variations in the aerosol dynamic using $355 \mathrm{~nm}$.

The $K_{\mathrm{RCS}}^{\text {corr }}(z)$ obtained from the wavelength $1064 \mathrm{~nm}$ presents values higher than 3 from the bottom up to around

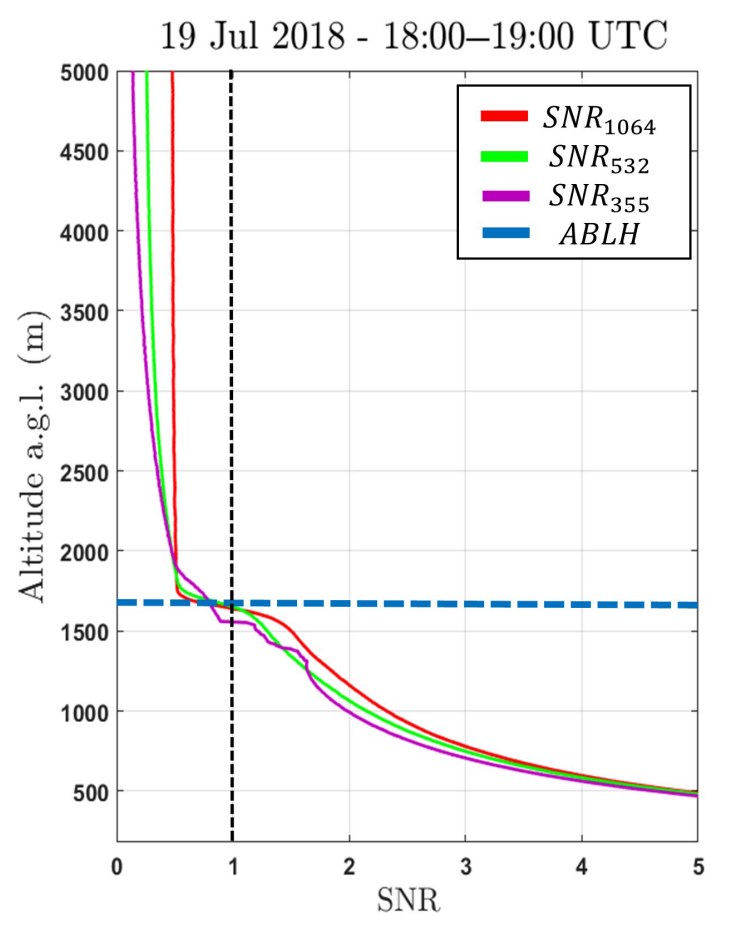

Figure 10. Signal-to-noise-ratio (SNR) profile of the three wavelengths (1064 nm; red line, $532 \mathrm{~nm}$ green line; and $355 \mathrm{~nm}$, violet line) obtained on 19 July 2018 between 18:00 and 19:00 UTC.

$1300 \mathrm{~m}$ in altitude, characterizing a region with a low degree of mixing. From $1300 \mathrm{~m}$ up to the ABLH the $K_{\mathrm{RCS}}^{\text {corr }}(z)$ has values lower than 3 , which characterize this region as showing a large degree of mixing and (in a more evident way) the presence of turbulence. Such behavior occurs mainly due to entrainment of cleaner air. A few meters above the ABLH, the $K_{\mathrm{RCS}}^{\mathrm{corr}}(z)$ has a great peak, which occurs due to rare aerosol plumes penetrating at this region. Such behavior was also observed in case study I, as well as by Pal et al. (2010) and McNicholas and Turner (2014). Above the ABLH the profile only has values higher than 3 ; however, as $\tau_{\mathrm{RCS}}^{\text {corr }}(z)$ decreases to values close to zero and low values of SNR of the RCS are characteristic of this region, it is not possible to extract conclusive information from $K_{\mathrm{RCS}}^{\mathrm{corr}}(z)$. In the same way as the comparison performed with other variables, the $K_{\mathrm{RCS}}^{\text {corr }}(z)$ obtained from the wavelength $532 \mathrm{~nm}$ presents similar behavior to the profile obtained from $1064 \mathrm{~nm}$, thus the same phenomena can be observed. On the other hand, the $K_{\mathrm{RCS}}^{\text {corr }}(z)$ obtained from the wavelength $355 \mathrm{~nm}$ does not allow for observing the behavior detected in the profile obtained from the reference wavelength because along the whole profile the $K_{\mathrm{RCS}}^{\text {corr }}(z)$ at $355 \mathrm{~nm}$ presents values higher than 3.

Figure 13 shows the composition signal of $\beta_{\text {aer }}$ and $\beta_{\text {mol }}$, retrieved during the analyzed period of this case study (18:00-19:00 UTC) using the Klett-Fernald-Sasano inversion (Klett, 1983, 1985; Fernald, 1984; Sasano and Nakane, 


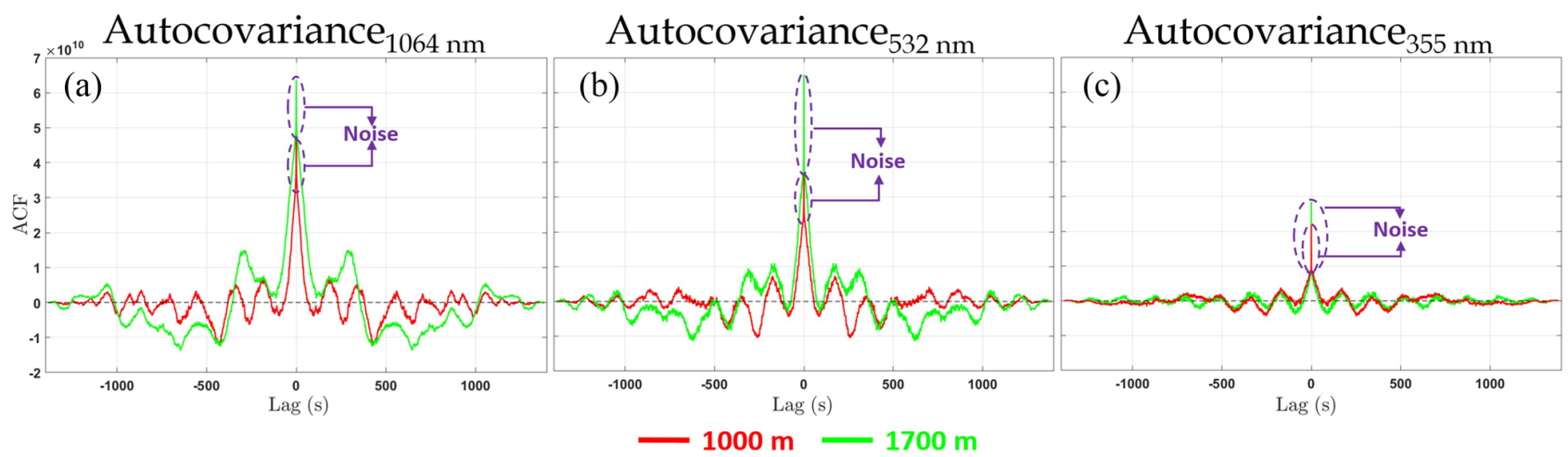

Figure 11. Autocovariance function at 1064 (a), 532 (b) and $355 \mathrm{~nm}$ (c) on 19 July 2018 from 18:00 to 19:00 UTC.
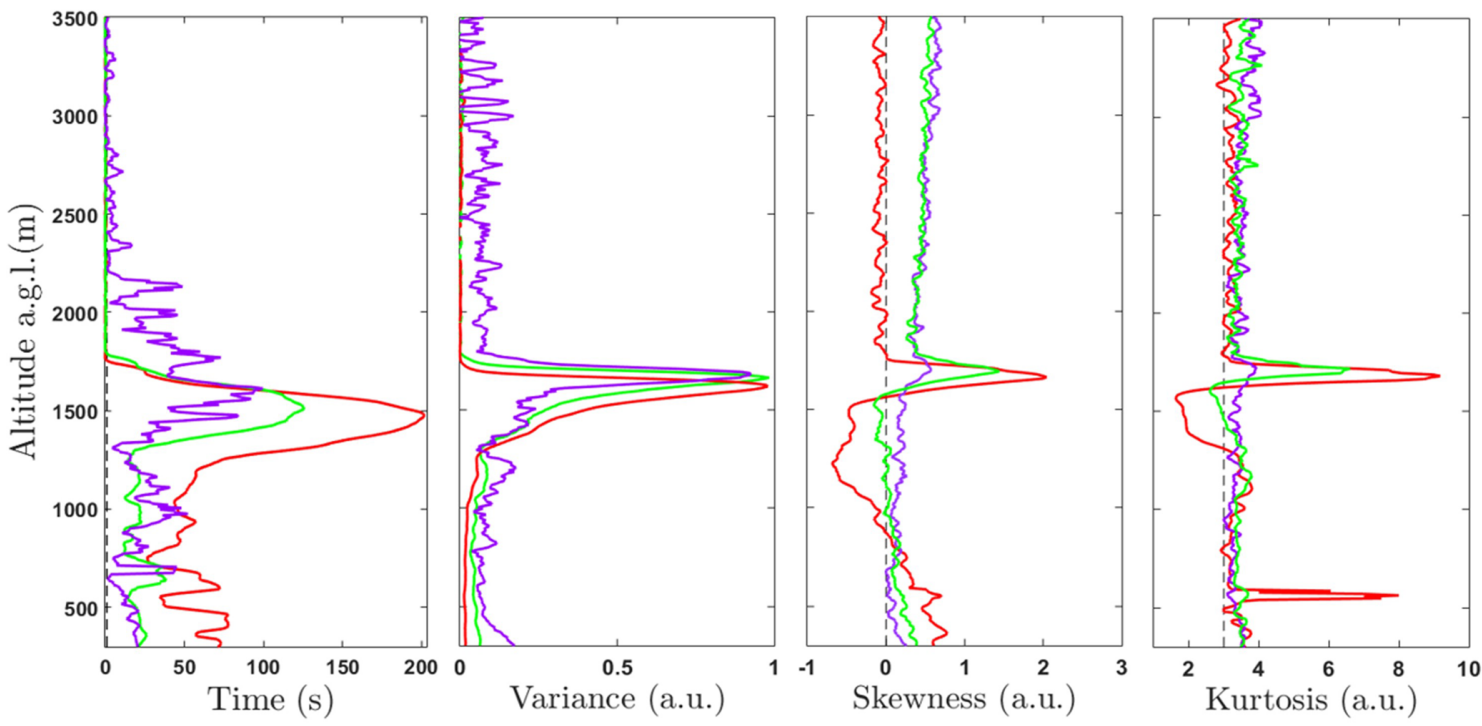

$1064 \mathrm{~nm}$

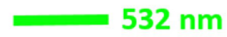

$355 \mathrm{~nm}$

Figure 12. High-order moments corrected by first lag correction at 1064 (red line), 532 (green line) and 355 nm (violet line) on 19 July 2018 from 18:00 to 19:00 UTC.

1984), at each one of the three wavelengths, as well as the $\beta_{\text {ratio }}$ calculated using the backscatter profile of aerosol and molecular component (Bucholtz, 1995). From Fig. 13.1 it is possible to observe that the backscattered signal at $1064 \mathrm{~nm}$ has a predominance of $\beta_{\mathrm{aer}}$, with almost null values of $\beta_{\mathrm{mol}}$. The composition of the backscattered signal at $532 \mathrm{~nm}$ is shown in Fig. 13.3. Although the component $\beta_{\text {mol }}$ has values higher than the ones observed in wavelength $1064 \mathrm{~nm}$, the component $\beta_{\text {aer }}$ is predominant in the backscattered signal composition. The backscattered signal at $355 \mathrm{~nm}$, presented in Fig. 13.5, unlike the other wavelengths, is predominantly composed of $\beta_{\mathrm{mol}}$ and has a low percentage of $\beta_{\mathrm{aer}}$.

From the results obtained in both case studies, it is possible to observe the influence of the wavelength in the proposed methodology. The wavelength $1064 \mathrm{~nm}$, considered our signal reference, has a negligible influence on component molecules; therefore, the backscatter signal retrieved at $1064 \mathrm{~nm}$ can be considered approximately equal to the backscatter signal retrieved only by the aerosol contribution, $\beta_{1064} \approx \beta_{\text {aer }}$. Before taking into account the approximation demonstrated in Eq. (5) $\left(\mathrm{RCS}_{1064} \approx \beta_{1064}\right)$, we can conclude that the range-corrected signal retrieved from a lidar at $1064 \mathrm{~nm}$ can be considered, with good precision, approximately equal to the backscatter signal retrieved at the same wavelength for aerosol components, $\mathrm{RCS}_{1064} \approx \beta_{\text {aer }}$. Such a relation enables the observation of behavior of aerosol plumes from high-order moments. In the case of wavelength $532 \mathrm{~nm}, \beta_{532}$ is composed of $\beta_{\text {aer }}$ and $\beta_{\text {mol }}\left(\beta_{532}=\beta_{\text {aer } 532}+\right.$ $\beta_{\text {mol }_{53}}$ ); however, as shown in Figs. 8 and 13 , there is a predominance of $\beta_{\text {aer }}$. Although the high-order moment profiles obtained from the wavelength $532 \mathrm{~nm}$ are noisier than that one generated from the reference wavelength data, the phenomena observed from the $1064 \mathrm{~nm}$ data can also be observed in $532 \mathrm{~nm}$ data, mainly after the application of first 


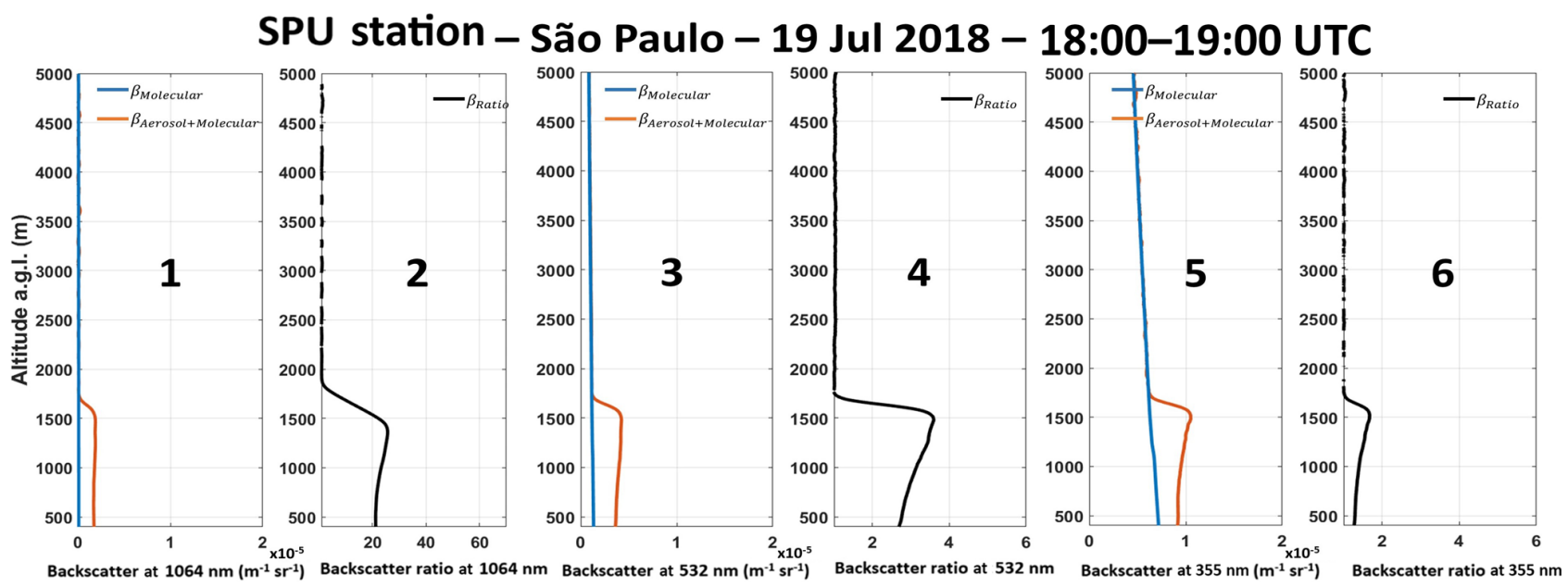

Figure 13. Total (aerosol and molecular) backscatter profile and backscatter ratio retrieved using Klett-Fernald-Sasano inversion technique for 1064, 532 and $355 \mathrm{~nm}$, respectively, for data retrieved on 19 July 2018 from 18:00 to 19:00 UTC.

lag correction. Consequently, the wavelength at $532 \mathrm{~nm}$ can be used in the proposed methodology providing satisfactory results. On the other hand, the backscatter at $355 \mathrm{~nm}$ is predominantly composed of $\beta_{\mathrm{mol}}$ and has a small percentage of $\beta_{\text {aer }}$, as presented in Figs. 8 and 13 .

This fact justifies the low quality observed in the results retrieved using the wavelength of $355 \mathrm{~nm}$. As established in Eq. (3), the turbulent variable is directly associated with $\beta^{\prime}{ }_{\text {aer }}$, but, due to the low contribution of this component in the backscatter signal at $355 \mathrm{~nm}$, the supposition established in Eq. (6) cannot be applied. Consequently, the high-order moments obtained from the proposed methodology are noisier and the value of $\tau_{\mathrm{RCS}^{\prime}}(z)$ is almost half of the value obtained from the reference wavelength, both due to influence of $\beta_{\mathrm{mol}}$ that presents the stronger contribution to the total backscatter coefficient at this wavelength. Therefore, the behavior observed in the high-order moment profiles generated from the $1064 \mathrm{~nm}$ wavelength data can be detected as partially (or even totally) suppressed as the complexity of highorder moments increases. In both case studies it was possible to observe from the third-order moment (skewness) that the results obtained from the wavelength $355 \mathrm{~nm}$ provide misinformation.

\section{Conclusions}

In this paper we performed a comparative analysis about the use of different wavelengths $(355,532$ and $1064 \mathrm{~nm})$ in studies about turbulence. The data were acquired with an elastic lidar, from the SPU lidar station of LALINET, by measurements gathered at high frequency $(0.5 \mathrm{~Hz})$ from July 2017 to July 2018. The RCS provided by this system was used to calculate high-order moments (variance, skewness and kurtosis) and the integral timescale, which were applied to characterization of aerosol dynamics. Based on previous studies, the wavelength $1064 \mathrm{~nm}$ was adopted as reference due to predominance of $\beta_{\text {aer. }}$.

Two case studies (26 July 2017 and 19 July 2018) were performed in order to verify the proposed methodology, as well as the applicability of each wavelength. In both cases, the results obtained from $1064 \mathrm{~nm}$ wavelength demonstrate that the high-order moments can support a detailed analysis of the ABL region. In addition, it is remarkable that the values of $\tau_{\mathrm{RCS}}$ in the region below the ABLH demonstrates the viability of the proposed methodology. The high-order moments obtained from the wavelength $532 \mathrm{~nm}$ are slightly more influenced by the noise than the results obtained from the reference wavelength (the value of noise can be observed by the $\mathrm{ACF}_{532}$. However, the same phenomena observed in the high-order moment profiles generated from the $1064 \mathrm{~nm}$ wavelength can be observed in the one generated from the wavelength $532 \mathrm{~nm}$, mainly with the application of first lag correction. On the other hand, the high-order moments obtained from $355 \mathrm{~nm}$ have a strong presence of noise, and thus the phenomena presented in the high-order moments obtained from $1064 \mathrm{~nm}$ wavelength cannot be observed from the third-order moment (skewness) in $355 \mathrm{~nm}$ high-order moment profiles.

The analysis of the backscatter signal at each wavelength shows that for both case studies $\beta_{\text {aer }}$ is the predominant contribution at $532 \mathrm{~nm}$, while $\beta_{\mathrm{mol}}$ is predominant at $355 \mathrm{~nm}$. In this way, the high-order statistics become noisier at $355 \mathrm{~nm}$ and cannot be applied in the proposed methodology. In contrast, the predominance of $\beta_{\text {aer }}$ at $532 \mathrm{~nm}$ implicates that this wavelength provides results similar to those obtained at $1064 \mathrm{~nm}$, especially after the application of first lag correction. Consequently, the $532 \mathrm{~nm}$ wavelength can be used to apply the proposed methodology, providing results similar to that obtained from $1064 \mathrm{~nm}$ wavelength. 
The results obtained in this paper show the viability of the proposed methodology and its applicability to the $532 \mathrm{~nm}$ wavelength, due to the similarity with results derived at $1064 \mathrm{~nm}$ and the evidence of a low $\varepsilon$ influence. On the other hand, the wavelength $355 \mathrm{~nm}$ does not provide satisfactory results in such a methodology due to the predominance of molecular signal in its composition. However, a better assessment of the molecular backscatter at 355 can reduce the influence of the noise caused by molecular signal and improve the results obtained from the data generated from this channel. In addition, the high-order moments obtained from the SPU lidar station using an elastic lidar data provided us with detailed information about some phenomena in the ABL, giving us a better comprehension of the aerosol dynamics.

Data availability. Data used in this paper are available upon request from corresponding author (gregori.moreira@usp.br).

Supplement. The supplement related to this article is available online at: https://doi.org/10.5194/amt-12-4261-2019-supplement.

Author contributions. The conceptualization was done by GdAM, JLGR and LAA. The methodology was done by GdAM, JLGR and LAA. The analysis software was developed by GdAM. The experiments were designed by GdAM. The data acquisition was performed by GdAM, FJSL, JJS and AAG. The formal analysis, investigation, writing of the original draft, preparation and review of the writing, and editing were performed by GdAM, FJSL, JLGR and LAA. The supervision, project administration and funding acquisition were done by LAA and EL.

Competing interests. The authors declare that they have no conflict of interest.

Acknowledgements. This work was supported by the Andalusia Regional Government, through the project P12-RNM-618 2409, the Spanish Agencia Estatal de Investigación (AEI), through projects CGL2016-81092-R, CGL2017-90884-REDT and CGL2017-83538-C3-1-R, and the Spanish Ministry of Economy and Competitiveness through projects CGL2016-81092-R, and CGL2017-90884-REDT. We acknowledge the financial support by the European Union's Horizon 2020 research and innovation program through project ACTRIS-2 (grant agreement no. 621654109). The authors gratefully acknowledge the University of Granada that supported this study through the Excellence Units Program and "Plan Propio. Programa 9 Convocatoria 2013". The authors would also like to acknowledge The National Council for Scientific and Technological Development (CNPQ) for their support (projects 152156/2018-6, 432515/2018-6 and 150716/2017-6), the São Paulo Research Foundation (FAPESP; grant no. 2015/12793-0) and the FEDER program for the University of Granada that supported this study through the Excellence Units Program.
Financial support. This research has been supported by the Andalusian Regional Government (P12-RNM-618 2409 project), the Spanish Agencia Estatal de Investigación (AEI, CGL2016-81092R, CGL2017-90884-REDT and CGL2017-83538-C3-1-R projects), the Spanish Ministry of Economy and Competitiveness (CGL201681092-R, and CGL2017-90884-REDT projects), the European Union's Horizon 2020 project (NACTRIS 2, grant no. 621654109), the University of Granada, the National Council for Scientific and Technological Development (CNPQ, 152156/2018-6, 432515/2018-6 and 150716/2017-6 projects), the São Paulo Research Foundation (FAPESP, grant no. 2015/12793-0), and the FEDER program for the University of Granada.

Review statement. This paper was edited by Vassilis Amiridis and reviewed by three anonymous referees.

\section{References}

Andrews, E., Sheridan, P. J., Ogren, J. A., and Ferrare, R.: In situ aerosol profiles over the Southern Great Plains cloud and radiation test bed site: 1. Aerosol optical properties, J. Geophys. Res.Atmos., 109, D06208, https://doi.org/10.1029/2003JD004025, 2004.

Antuña Marrero, J. C., Landulfo, E., Estevan, R., Barja, B., Robock, A., Wolfram, E., Ristori, P., Clemesha, B., Zaratti, F., Forno, R., Armandillo, E., Bastidas, A. E., de Frutos Baraja, A. M., Whiteman, D. N., Quel, E., Barbosa, H. M. J., Lopes, F., Montilla-Rosero, E., and Guerrero-Rascado, J. L.: LALINET: The First Latin American-Born Regional Atmospheric Observational Network, B. Am. Meteorol. Soc., 98, 1255-1275, https://doi.org/10.1175/BAMS-D-15-00228.1, 2017.

Baars, H., Ansmann, A., Engelmann, R., and Althausen, D.: Continuous monitoring of the boundary-layer top with lidar, Atmos. Chem. Phys., 8, 7281-7296, https://doi.org/10.5194/acp-8-72812008, 2008.

Bravo-Aranda, J. A., de Arruda Moreira, G., Navas-Guzmán, F., Granados-Muñoz, M. J., Guerrero-Rascado, J. L., PozoVázquez, D., Arbizu-Barrena, C., Olmo Reyes, F. J., Mallet, M., and Alados Arboledas, L.: A new methodology for PBL height estimations based on lidar depolarization measurements: analysis and comparison against MWR and WRF model-based results, Atmos. Chem. Phys., 17, 6839-6851, https://doi.org/10.5194/acp-17-6839-2017, 2017.

Bucholtz, A.: Rayleigh-scattering calculations for the terrestrial atmosphere, Appl. Opt., 34, 2765-2773, https://doi.org/10.1364/AO.34.002765, 1995.

de Arruda Moreira, G., Guerrero-Rascado, J. L., Benavent-Oltra, J. A., Ortiz-Amezcua, P., Román, R., E. Bedoya-Velásquez, A., Bravo-Aranda, J. A., Olmo Reyes, F. J., Landulfo, E., and Alados-Arboledas, L.: Analyzing the turbulent planetary boundary layer by remote sensing systems: the Doppler wind lidar, aerosol elastic lidar and microwave radiometer, Atmos. Chem. Phys., 19, 1263-1280, https://doi.org/10.5194/acp-191263-2019, 2019.

Eck, T. F., Holben, B. N., Reid, J. S., Dubovik, O., Smirnov, A., O'Neill, N. T., Slutsker, I., and Kinne, S.: Wavelength dependence of the optical depth of biomass burning, urban, and 
desert dust aerosols, J. Geophys. Res.-Atmos., 104, 3133331349, https://doi.org/10.1029/1999JD900923, 1999.

Emeis, S.: Surface-Based Remote Sensing of the Atmospheric Boundary Layer, Atmospheric and Oceanographic Sciences Libraty, Vol. 40, Springer Heidelberg, https://doi.org/10.1007/97890-481-9340-0, 2011.

Engelmann, R., Wandinger, U., Ansmann, A., Müller, D., Zeromskis, E., Althausen, D., and Wehner, B.: Lidar Observations of the Vertical Aerosol Flux in the Planetary Boundary Layer, J. Atmos. Ocean. Technol., 25, 1296-1306, https://doi.org/10.1175/2007JTECHA967.1, 2008.

Feingold, G. and Morley, B.: Aerosol hygroscopic properties as measured by lidar and comparison with in situ measurements, J. Geophys. Res., 108, 4327, https://doi.org/10.1029/2002JD002842, 2003.

Fernald, F. G.: Analysis of atmospheric lidar observations: some comments, Appl. Opt., 23, 652-653, https://doi.org/10.1364/AO.23.000652, 1984.

Guerrero-Rascado, J. L., Landulfo, E., na, J. C. A., de Melo Jorge Barbosa, H., Barja, B., Álvaro Efrain Bastidas, Bedoya, A. E., da Costa, R. F., Estevan, R., Forno, R., Gouveia, D. A., Jiménez, C., calves Larroza, E. G., da Silva Lopes, F. J., Montilla-Rosero, E., de Arruda Moreira, G., Nakaema, W. M., Nisperuza, D., Alegria, D., Múnera, M., Otero, L., Papandrea, S., Pallota, J. V., Pawelko, E., Quel, E. J., Ristori, P., Rodrigues, P. F., Salvador, J., Sánchez, M. F., and Silva, A.: Latin American Lidar Network (LALINET) for aerosol research: Diagnosis on network instrumentation, J. Atmos. Sol.-Terr. Phys., 138/139, 112-120, https://doi.org/10.1016/j.jastp.2016.01.001, 2016.

Hammann, E., Behrendt, A., Le Mounier, F., and Wulfmeyer, V.: Temperature profiling of the atmospheric boundary layer with rotational Raman lidar during the $\mathrm{HD}(\mathrm{CP})^{2}$ Observational Prototype Experiment, Atmos. Chem. Phys., 15, 2867-2881, https://doi.org/10.5194/acp-15-2867-2015, 2015.

Heese, B., Flentje, H., Althausen, D., Ansmann, A., and Frey, S.: Ceilometer lidar comparison: backscatter coefficient retrieval and signal-to-noise ratio determination, Atmos. Meas. Tech., 3, 1763-1770, https://doi.org/10.5194/amt-3-1763-2010, 2010.

Holben, B., Eck, T., Slutsker, I., Tanré, D., Buis, J., Setzer, A., Vermote, E., Reagan, J., Kaufman, Y., Nakajima, T., Lavenu, F., Jankowiak, I., and Smirnov, A.: AERONET-A Federated Instrument Network and Data Archive for Aerosol Characterization, Remote Sens. Environ., 66, 1-16, https://doi.org/10.1016/S0034-4257(98)00031-5, 1998a.

Holben, B. N., Eck, T. F., Slutsker, I., Tanré, D., Buis, J. P., Setzer, A., Vermote, E., Reagan, J. A., Kaufman, Y. J., Nakajima, T., Lavenu, F., Jankowiak, I., and Smirnov, A.: Aeronet - A Federal Instrument Network and Data Archive for Aerosol Characterization, Remote Sens. Environ., 66, 1-16, https://doi.org/10.1016/S0034-4257(98)00031-5, 1998b.

Hooper, W. P. and Eloranta, E. W.: Lidar Measurements of Wind in the Planetary Boundary Layer: The Method, Accuracy and Results from Joint Measurements with Radiosonde and Kytoon, J. Clim. Appl. Meteor., 25, 990-1001, 1986.

Kaimal, J. C. and Gaynor, J. E.: The Boulder Atmospheric Observatory, J. Clim. Appl. Meteor., 22, 863-880, https://doi.org/10.1175/15200450(1983)022<0863:TBAO>2.0.CO;2, 1983.
Kiemle, C., Ehret, G., Fix, A., Wirth, M., Poberaj, G., Brewer, W. A., Hardesty, R. M., Senff, C., and LeMone, M. A.: Latent Heat Flux Profiles from Collocated Airborne Water Vapor and Wind Lidars during IHOP_2002, J. Atmos. Ocean. Technol., 24, 627-639, https://doi.org/10.1175/JTECH1997.1, 2007.

Klett, J. D.: Lidar calibration and extinction coefficients, Appl. Opt., 22, 514-515, https://doi.org/10.1364/AO.22.000514, 1983.

Klett, J. D.: Lidar inversion with variable backscatter/extinction ratios, Appl. Opt., 24, 1638-1643, https://doi.org/10.1364/AO.24.001638, 1985.

Lagouarde, J.-P., Commandoire, D., Irvine, M., and Garrigou, D.: Atmospheric boundary-layer turbulence induced surface temperature fluctuations. Implications for TIR remote sensing measurements, Remote Sens. Environ., 138, 189-198, https://doi.org/10.1016/j.rse.2013.06.011, 2013.

Lagouarde, J.-P., Irvine, M., and Dupont, S.: Atmospheric turbulence induced errors on measurements of surface temperature from space, Remote Sens. Environ., 168, 40-53, https://doi.org/10.1016/j.rse.2015.06.018, 2015.

Lenschow, D. H., Wyngaard, J. C., and Pennell, W. T.: Mean-Field and Second-Moment Budgets in a Baroclinic, Convective Boundary Layer, J. Atmos. Sci., 37, 1313-1326, https://doi.org/10.1175/15200469(1980)037<1313:MFASMB>2.0.CO;2, 1980.

Lenschow, D. H., Mann, J., and Kristensen, L.: How Long Is Long Enough When Measuring Fluxes and Other Turbulence Statistics?, J. Atmos. Ocean. Technol., 11, 661-673, https://doi.org/10.1175/15200426(1994)011<0661:HLILEW>2.0.CO;2, 1994.

Lenschow, D. H., Wulfmeyer, V., and Senff, C.: Measuring Secondthrough Fourth-Order Moments in Noisy Data, J. Atmos. Ocean. Technol., 17, 1330-1347, https://doi.org/10.1175/15200426(2000)017<1330:MSTFOM>2.0.CO;2, 2000.

Lopes, F. J. S., Luis Guerrero-Rascado, J., Benavent-Oltra, J. A., Román, R., Moreira, G. A., Marques, M. T. A., da Silva, J. J., Alados-Arboledas, L., Artaxo, P., and Landulfo, E.: Rehearsal for Assessment of atmospheric optical Properties during biomass burning Events and Longrange transportation episodes at Metropolitan Area of São Paulo-Brazil (RAPEL), EPJ Web Conf., 176, 08011, https://doi.org/10.1051/epjconf/201817608011, 2018.

Lothon, M., Lenschow, D., and Mayor, S.: Coherence and Scale of Vertical Velocity in the Convective Boundary Layer from a Doppler Lidar, Bound.-Lay. Meteorol., 121, 521-536, https://doi.org/10.1007/s10546-006-9077-1, 2006.

Martucci, G., Matthey, R., Mitev, V., and Richner, H.: Comparison between Backscatter Lidar and Radiosonde Measurements of the Diurnal and Nocturnal Stratification in the Lower Troposphere, J. Atmos. Ocean. Technol., 24, 1231-1244, https://doi.org/10.1175/JTECH2036.1, 2007.

McNicholas, C. and Turner, D. D.: Characterizing the convective boundary layer turbulence with a High Spectral Resolution Lidar, J. Geophys. Res.-Atmos., 119, 12910-12927, https://doi.org/10.1002/2014JD021867, 2014.

Menut, L., Flamant, C., Pelon, J., and Flamant, P. H.: Urban boundary-layer height determination from lidar measurements over the Paris area, Appl. Opt., 38, 945-954, https://doi.org/10.1364/AO.38.000945, 1999. 
Monin, A. S. and Yaglom, A. M.: Statistical Fluid Mechanics, Vol. 2, MIT Press, 874 pp., 1979.

Muppa, S. K., Behrendt, A., Späth, F., Wulfmeyer, V., Metzendorf, S., and Riede, A.: Turbulent Humidity Fluctuations in the Convective Boundary Layer: Case Studies Using Water Vapour Differential Absorption Lidar Measurements, Bound.-Lay. Meteorol., 158, 43-66, https://doi.org/10.1007/s10546-015-0078-9, 2016.

O'Connor, E. J., Illingworth, A. J., Brooks, I. M., Westbrook, C. D., Hogan, R. J., Davies, F., and Brooks, B. J.: A Method for Estimating the Turbulent Kinetic Energy Dissipation Rate from a Vertically Pointing Doppler Lidar, and Independent Evaluation from Balloon-Borne In Situ Measurements, J. Atmos. Ocean. Technol., 27, 1652-1664, https://doi.org/10.1175/2010JTECHA1455.1, 2010.

Pal, S., Behrendt, A., and Wulfmeyer, V.: Elastic-backscatter-lidarbased characterization of the convective boundary layer and investigation of related statistics, Ann. Geophys., 28, 825-847, https://doi.org/10.5194/angeo-28-825-2010, 2010.

Pappalardo, G., Amodeo, A., Apituley, A., Comeron, A., Freudenthaler, V., Linné, H., Ansmann, A., Bösenberg, J., D’Amico, G., Mattis, I., Mona, L., Wandinger, U., Amiridis, V., AladosArboledas, L., Nicolae, D., and Wiegner, M.: EARLINET: towards an advanced sustainable European aerosol lidar network, Atmos. Meas. Tech., 7, 2389-2409, https://doi.org/10.5194/amt7-2389-2014, 2014.

Poltera, Y., Martucci, G., Collaud Coen, M., Hervo, M., Emmenegger, L., Henne, S., Brunner, D., and Haefele, A.: PathfinderTURB: an automatic boundary layer algorithm. Development, validation and application to study the impact on in situ measurements at the Jungfraujoch, Atmos. Chem. Phys., 17, 1005110070, https://doi.org/10.5194/acp-17-10051-2017, 2017.

Sasano, Y. and Nakane, H.: Significance of the extinction/backscatter ratio and the boundary value term in the solution for the two-component lidar equation, Appl. Opt., 23, 1-13, https://doi.org/10.1364/AO.23.0011_1, 1984.

Stull, R.: An Introduction to Boundary Layer Meteorology, Atmospheric and Oceanographic Sciences Library, Springer Netherlands, 1988.

Stull, R., Santoso, E., Berg, L., and Hacker, J.: Boundary Layer Experiment 1996 (BLX96), B. Am. Meteorol. Soc., 78, 1149-1158, https://doi.org/10.1175/15200477(1997)078<1149:BLEB>2.0.CO;2, 1997.

Titos, G., Cazorla, A., Zieger, P., Andrews, E., Lyamani, H., Granados-Muñoz, M., Olmo, F., and Alados-Arboledas, L.: Effect of hygroscopic growth on the aerosol lightscattering coefficient: A review of measurements, techniques and error sources, Atmos. Environ., 141, 494-507, https://doi.org/10.1016/j.atmosenv.2016.07.021, 2016.
Turner, D. D., Ferrare, R. A., Wulfmeyer, V., and Scarino, A. J.: Aircraft Evaluation of Ground-Based Raman Lidar Water Vapor Turbulence Profiles in Convective Mixed Layers, J. Atmos. Ocean. Technol., 31, 1078-1088, https://doi.org/10.1175/JTECH-D-13-00075.1, 2014.

Veselovskii, I., Whiteman, D. N., Korenskiy, M., Suvorina, A., and Pérez-Ramírez, D.: Use of rotational Raman measurements in multiwavelength aerosol lidar for evaluation of particle backscattering and extinction, Atmos. Meas. Tech., 8, 41114122, https://doi.org/10.5194/amt-8-4111-2015, 2015.

Vogelmann, A. M., McFarquhar, G. M., Ogren, J. A., Turner, D. D., Comstock, J. M., Feingold, G., Long, C. N., Jonsson, H. H., Bucholtz, A., Collins, D. R., Diskin, G. S., Gerber, H., Lawson, R. P., Woods, R. K., Andrews, E., Yang, H.-J., Chiu, J. C., Hartsock, D., Hubbe, J. M., Lo, C., Marshak, A., Monroe, J. W., McFarlane, S. A., Schmid, B., Tomlinson, J. M., and Toto, T.: RACORO Extended-Term Aircraft Observations of Boundary Layer Clouds, B. Am. Meteorol. Soc., 93, 861-878, https://doi.org/10.1175/BAMS-D-11-00189.1, 2012.

Wang, Z., Cao, X., Zhang, L., Notholt, J., Zhou, B., Liu, R., and Zhang, B.: Lidar measurement of planetary boundary layer height and comparison with microwave profiling radiometer observation, Atmos. Meas. Tech., 5, 1965-1972, https://doi.org/10.5194/amt-5-1965-2012, 2012.

Lidar: Range-Resolved Optical Remote Sensing of the Atmosphere, Springer Series in Optical Sciences, Springer New York, 2005.

Welton, E. J., Campbell, J. R., Spinhirne, J. D., and Scott, V. S.: Global monitoring of clouds and aerosols using a network of micropulse lidar systems, Proc. SPIE 4153, Lidar Remote Sensing for Industry and Environment Monitoring, https://doi.org/10.1117/12.417040, 2001.

Williams, A. G. and Hacker, J. M.: The composite shape and structure of coherent eddies in the convective boundary layer, Bound.-Lay. Meteorol., 61, 213-245, https://doi.org/10.1007/BF02042933, 1992.

Wulfmeyer, V.: Investigation of Turbulent Processes in the Lower Troposphere with Water Vapor DIAL and Radar-RASS, J. Atmos. Sci., 56, 1055-1076, https://doi.org/10.1175/15200469(1999)056<1055:IOTPIT>2.0.CO;2, 1999.

Wulfmeyer, V., Pal., S., Turner, D. D., and Wagner, E.: Can water vapor Raman lidar resolve profiles of turbulent variables in the convective boundary layer?, Bound.-Lay. Meteorol., 136, 253284, https://doi.org/10.1007/s10546-010-9494-z, 2010. 